\title{
Redes personales de africanos y latinoamericanos en Cataluña, España. Análisis reticular de integración y cambio
}

\author{
Javier Ávila Molero - Departament d'Antropologia social i cultural - UAB ${ }^{1}$
}

\section{Resumen}

El artículo analiza comparativamente las redes personales de los inmigrantes argentinos, dominicanos, marroquíes y senegaleses/gambianos en Cataluña, España. Su objetivo es identificar los vínculos entre las variables de estructura y composición de estas redes, con los procesos de integración de los inmigrantes en la sociedad receptora. Finalmente, se analiza las dinámicas que desarrollan las redes personales y la relación de sus procesos de cambio interno con los procesos de transnacionalismo con la sociedad de origen.

Palabras clave: Redes sociales - Redes personales - Migración internacional Transnacionalismo

\begin{abstract}
This paper analyzes, in comparative way, the personal networks of Argentinian, Dominican, Moroccan and Senegambian immigrants in Catalonia, Spain. The main objetive is to analyze relations structure and composition, and their relatios with the process of insertion of the immigrants in the destination society. This is possible by the development of new indicator. In the same way, this paper it also analyzes the strong processes of change in the structure and composition of the personal networks of the immigrants.
\end{abstract}

Key words: Social Networks - Personal Networks - International migration Transnacionalism.

\section{I ntroducción ${ }^{2}$}

El año 2004 empezó el proyecto titulado Development of a social network of acculturarion and its applications to inmigrant populations in south Florida and the northeastern Spain ${ }^{3}$. El objetivo de este proyecto era analizar, de manera comparativa, las redes personales de los colectivos inmigrantes de Argentina, República Dominicana, Marruecos y Senegal/Gambia en Cataluña, España, para comprender su funcionamiento y tipo de relación con los procesos de integración.

En esa primera fase se recogieron en Cataluña 300 redes personales. La principal herramienta para el trabajo de campo fue el software especializado en análisis de redes personales Egonet ${ }^{4}$. En cada uno de los 300 casos, este software permitió

\footnotetext{
${ }^{1}$ Correspondencia: Javier Ávila LavierAugusto.Avila@campus.uab.cat o javilamolero@hotmail.com

${ }^{2}$ Quiero expresar mi agradeciemiento a José Luis Molina, Isidro Maya y Ainhoa de Federico por las discusiones y sugerencias ofrecias a borradores preliminares de este documento.

${ }^{3}$ National Science Foundation, award no BCS-0417429, dirigido por Christopher McCarty en los Estados Unidos y José Luis Molina en España.

${ }^{4}$ http://sourceforge. net/projects/egonet/
} 
recoger información sobre ego y una muestra de 45 alteri de su red personal. Con esta información se hicieron análisis preliminares sobre las propiedades de estructura y composición de estas redes personales.

El año 2006 se inició una segunda fase en el estudio de las redes personales de los inmigrantes. En esta ocasión, el proyecto se tituló Dinamics of actors and networks across levels: individuals, groups, organizations and social settings ${ }^{5}$. El objetivo de este segundo proyecto era desarrollar un estudio longitudinal de redes personales, poniendo a prueba el software Siena, diseñado para el estudio de redes sociocéntricas. Para el estudio se escogió una muestra de 80 casos entre los 300 estudiados en la primera fase. A esta muestra de 80 casos, se volvió a aplicar, dos años después, una segunda encuesta de redes personales con Egonet, manteniendo los mismos criterios metodológicos de la primera fase del estudio. La información recogida ha permitido construir una base de datos con mucha información sobre los colectivos inmigrantes y sus redes personales. Esta información viene siendo ahora procesada en diversos proyectos por los miembros del equipo de Egolab ${ }^{6}$.

En nuestro caso hemos decidido escoger dos variables para el análisis de las redes personales de los inmigrantes: a) estructura de cluster y b) composición étnica de los alteri. El presente artículo ofrece un análisis sobre las características de estas dos variables en las redes personales de los inmigrantes y su relación con sus dinámicas de cambio, en sus procesos de integración en la sociedad receptora.

\section{Migración y redes personales}

En la actualidad, el concepto de redes sociales se ha convertido en moneda corriente en los estudios sobre migración internacional. Existe una conciencia creciente sobre la importancia de las redes en los procesos de migración e integración en la sociedad de destino. Se ha vuelto sentido común afirmar que las personas no emigran de manera aislada, sino más bien colectiva, precisamente a través de "redes"; y que estas conexiones son importantes para comprender las estrategias de inserción en la sociedad de destino.

Sin embargo, el concepto de redes sociales se suele usar más como metáfora que como herramienta de análisis. Como metáfora, este concepto se suele entender como los vínculos que desarrollan entre si los inmigrantes de un mismo país. La naturaleza social y cultural de estas redes sería endogámica. Desde esta perspectiva, cuando se habla de redes sociales en el fondo se habla de "redes

\footnotetext{
${ }^{5}$ European Collaborative Research Project (ECRP) financiado por la European Science Foundation y el Ministerio de Ciencia y Tecnología (SEJ 2005-25683-E, SEJ 2007-29468-E, 05_ECRP_FP026).

${ }^{6}$ www.egoredes.net.
} 
étnicas". Es decir, las redes que los inmigrantes desarrollan con sus connacionales, entendiendo que en contextos migratorios el origen nacional se constituye en uno de los principales registros desde donde se (re)construye la identificación entre el "nosotros" y los "otros".

El problema con el uso del concepto de redes sociales como metáfora es que dirige la reflexión hacia una perspectiva según la cual los inmigrantes "reproducirían" sus redes sociales originarias en la sociedad de destino. Desde nuestro punto de vista, esta perspectiva se enfoca sólo en una de las múltiples dimensiones de las redes sociales de los inmigrantes y no calibra, en su real dimensión, el impacto que el cambio de sociedad genera en las redes sociales del inmigrante.

En nuestro estudio hemos encontrado que en la totalidad de los casos, la estructura y composición de las redes sociales originarias se ven radicalmente redefinidas con la migración. La mayoría de las redes originarias suelen desaparecer, y las que se mantienen tienen que "reinventarse", en forma y contenido, desde un nuevo escenario translocal. Inclusive, aquellas redes en apariencia menos proclives al cambio, como las de parentesco.

Del mismo modo, el inmigrante tiene que "reinventar" nuevas redes sociales en la sociedad de destino. Estas redes pueden tener composición variable de paisanos, nativos de la sociedad de destino o inmigrantes de otras nacionalidades. Desde nuestra perspectiva, la estructura y composición de estas nuevas redes sociales ofrece información muy valiosa sobre el tipo de estrategia de integración que desarrolla un inmigrante de manera particular, y un colectivo inmigrante, de manera general ${ }^{7}$.

En su proceso de integración en la sociedad de destino, el inmigrante tiene que volver a reconstruir sus redes sociales. Este proceso es duro y complejo, y se desarrolla de manera problemática. No es para nada un simple "transplante" de "redes étnicas" originarias, como se suele sostener, sino más bien un proceso de reinvención de nuevas redes, que implica el desarrollo de una nueva sociabilidad y cultura, no sólo con los nativos de la sociedad receptora, sino también con los propios paisanos (connacionales) y los miembros de la red en la sociedad de origen cuyos vínculos han logrado subsistir. Desde nuestra perspectiva, este proceso de reinvención del conjunto de redes sociales, genera también la reinvención de ego.

\footnotetext{
${ }^{7}$ Isidro Maya Jariego - siguiendo a Ferrand (2005) y De federico (2005)- sostiene que las variables de estructura y composición de las redes personales de los inmigrantes pueden ser usados como indicadores para analizar las características de las comunidades que, a nivel "meso", conforman estos inmigrantes (comunicación personal).
} 


\section{Redes y comunidades personales}

Estudios recientes en el campo de las redes sociales han logrado definir, con mayor precisión, algunas características de las redes personales. En la actualidad se sabe que las redes personales de un ego tienen en promedio 290 alteri en su composición (Molina, 2007) y que desarrollan una desviación típica de 250 según criterios de clase social, raza, edad, género, entre otras variables.

Estas redes constituyen el "pequeño mundo" social a través del cual una persona formar parte de las estructuras mayores que denominamos "sociedad". Constituyen el fundamento de las denominadas comunidades de práctica, dentro de las cuales las personas desarrollamos lo fundamental de nuestra sociabilidad. Estas redes constituyen también el fundamento de las denominadas "comunidades personales" (Wellman, 1988).

A diferencia del concepto tradicional de comunidad, enfocado en criterios de pertenencia grupal y territorial, las comunidades personales se enfocan en criterios reticulares. De manera tradicional, los estudios de comunidad han definido su ámbito según criterios geográficos, más que sociales. Por esta razón, "comunidad" suele ser sinónimo de "localidad", o entorno geográfico próximo.

El problema de esta equivalencia entre "comunidad" y "localidad" es que asume que las interacciones más importantes de una persona se desarrollan dentro de su entorno geográfico más cercano. Y como bien sabemos, no siempre es así. En primer lugar, porque no necesariamente todas las personas de una localidad interactúan entre si. En segundo lugar, porque tampoco necesariamente todas las interacciones de una persona se circunscriben a su entorno local.

A diferencia del concepto tradicional de comunidad, que suele ser sinónimo de "localidad", el concepto de comunidad personal considera como unidad de análisis los ámbitos realmente existentes de sociabilidad de un sujeto, que pueden ser "locales", pero también "no-locales", como señala Ferrand (2002). Este replanteamiento es particularmente útil para repensar las comunidades inmigrantes, que hasta ahora han sido comprendidas mas como sinónimo de "diásporas" 8 .

\footnotetext{
${ }^{8}$ Este concepto es muy útil para el estudio de las comunidades transnacionales. Es necesario recordar que la migración internacional genera procesos simultáneos de des-estructuración y re-estructuración de las redes sociales en el inmigrante y sus contrapartes en los contextos de destino y origen. También que estos procesos no se desarrollan de manera mecánica. Por el contrario, son procesos complejos y problemáticos, heterogéneos en contenido, frecuencia e intensidad relacional, con diferentes estrategias de sociabilidad desarrolladas entre lo "local" y "no-local".
} 


\section{Repensar las comunidades inmigrantes}

En un mundo globalizado es necesario repensar la noción de comunidad transnacional, incorporando en la definición el ámbito de las redes sociales que sus miembros desarrollan. Estas redes no se limitan sólo a paisanos residentes en la sociedad de destino, sino incluyen también a connacionales en la sociedad de origen e, inclusive, en otros países extranjeros. Del mismo modo, estas redes suelen incluir también a personas naturales de la sociedad receptora y también a inmigrantes de otras nacionalidades extranjeras residentes en la misma sociedad de destino.

Por lo general, las comunidades transnacionales han sido entendidas como entidades cerradas y homogéneas, de fuertes vínculos internos, constituidas por inmigrantes de una misma nacionalidad de origen y con residencia compartida en la misma sociedad de destino. Esta sería una forma incompleta de entender las diásporas, porque no incluye, en la definición, las redes realmente existentes que sus miembros desarrollan, las cuales son, en la actualidad, cada vez más complejas, con un perfil sociocultural más diverso. Esta complejidad se puede apreciar en el siguiente gráfico, donde se representan las redes personales de un inmigrante varón argentino en Cataluña, España?

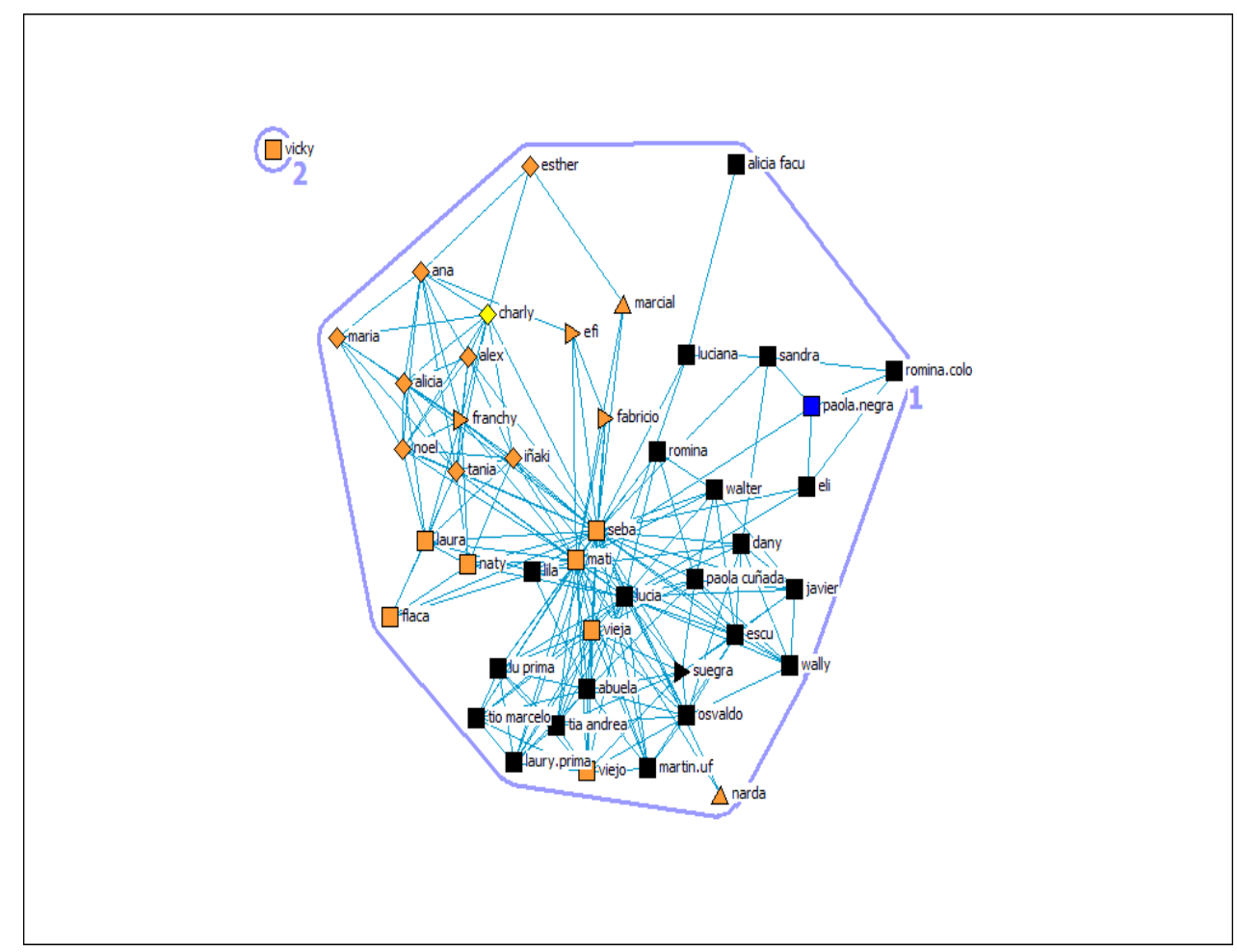

Gráfico 1. Representación la redes personal de un inmigrante argentino en España.

\footnotetext{
9 Esta red ha sido reconstruida con información recolectada sobre 45 alteri (miembros) de su red personal, durante el año 2006.
} 
El gráfico representa algunas variables muy básicas de la estructura y composición de la red personal del inmigrante: a) el cluster de la red, (la línea púrpura) muestra una estructura de redes densa y concentrada, b) el lugar de residencia de los miembros de su red (en naranja se representa los alteri que residen en España y en negro en Argentina) muestra una red transnacional, cuyos miembros radican de manera casi equitativamente en ambos países, c) la nacionalidad de origen de los miembros de esta red (la forma cuadrada representa personas de nacionalidad argentina; la de rombo personas de nacionalidad española y la de triángulo personas de otras nacionalidades), muestra una red multiétnica, especialmente en su ámbito desarrollado en España.

Este gráfico representa, de manera elemental y sencilla, el nuevo tipo de redes que los inmigrantes desarrollan en la actualidad, en un mundo globalizado, cada vez más interconectado, transnacional y multicultural, en donde las sociedades receptoras desarrollan lo que Vertovec ha definido como "super-diversidad" (Vertovec, 2007). Sostenemos que el estudio de las redes personales no sólo permite identificar las principales variables de estructura y composición de las comunidades personales, sino también dar cuenta de fenómenos poco estudiados como el "solapamiento de comunidades" en la sociabilidad transnacional de un inmigrante y la experiencia de sus múltiples pertenencias (Maya Jariego, 2004) dentro de este nuevo mundo de "super-diversidad".

\section{2. ¿Cómo analizar las comunidades personales inmigrantes?}

El análisis de las redes personales de los inmigrantes permite identificar las características de sus comunidades personales. También constituyen indicadores que permiten la caracterización de sus colectivos a nivel meso. En ese sentido, el análisis de estas redes personales ofrece importante información sobre los procesos de integración que se desarrollan.

En nuestro caso, nos vamos a enfocar en el análisis de dos variables de las redes personales: a) estructura de cluster y b) composición étnica de los alteri. La primera variable se refiere a las relaciones que desarrolla ego con sus alteri y también las relaciones que sus alteri desarrollan entre si. La segunda variable se refiere a las características personales de los alteri. En este caso, la nacionalidad de origen. Como ya hemos señalado líneas atrás, en escenarios migratorios, la nacionalidad de origen se convierte en uno de los principales registros desde el cual se desarrollan los procesos de "identificación" de los límites entre el "nosotros" y los "otros" entre el inmigrante y la sociedad receptora. 


\section{a. Estructura de cluster}

Las personas desarrollamos nuestros vínculos de sociabilidad de manera muchas veces aleatorias. Sin embargo, para que estos vínculos constituyan redes, requieren de cierta estabilidad en el tiempo. Esta estabilidad se obtiene a través de la reciprocidad que desarrollada la relación establecida entre un ego y su alter.

Cada relación de ego se desarrolla dentro de un ámbito de sociabilidad determinado. El conjunto de relaciones de ego con sus alteri desarrolla microestructuras al mismo tiempo que ofrece oportunidades a la sociabilidad de ego, también le supone límites.

Estas micro-estructuras son de diferentes características. En nuestra investigación hemos logrado identificar tres tipos de micro-estructuras: a) concentrada, b) bipolar y c) segmentada. En el primer caso, las concentradas se caracterizan por su entramado de red con densidad alta, concentrada en torno a un único cluster. En el segundo caso, las bipolares se caracterizan por un entramado de densidad intermedia y la concentración de sus redes en torno a dos clusters. Finalmente, en el tercer caso, las segmentadas se caracterizan por un entramado de densidad baja, y la dispersión de sus redes en tres o más clusters.

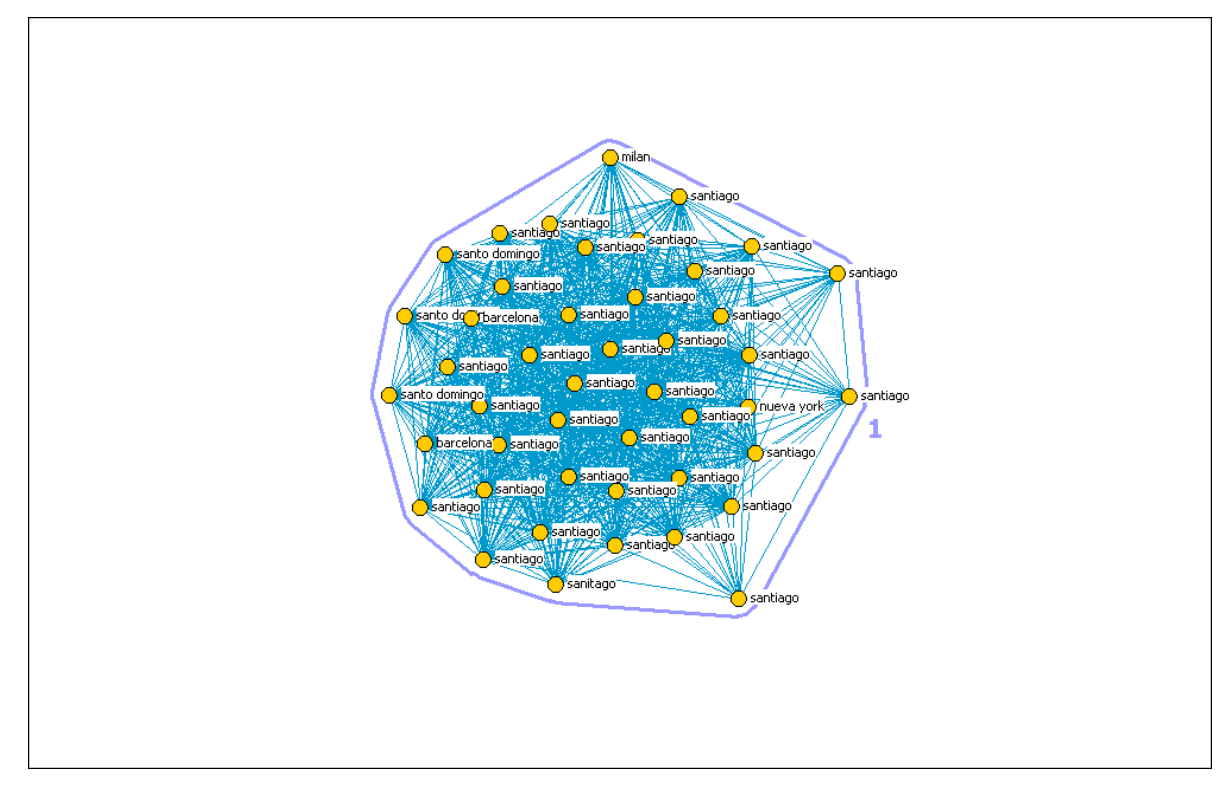

Gráfico 2. Micro-estructura concentrada. 


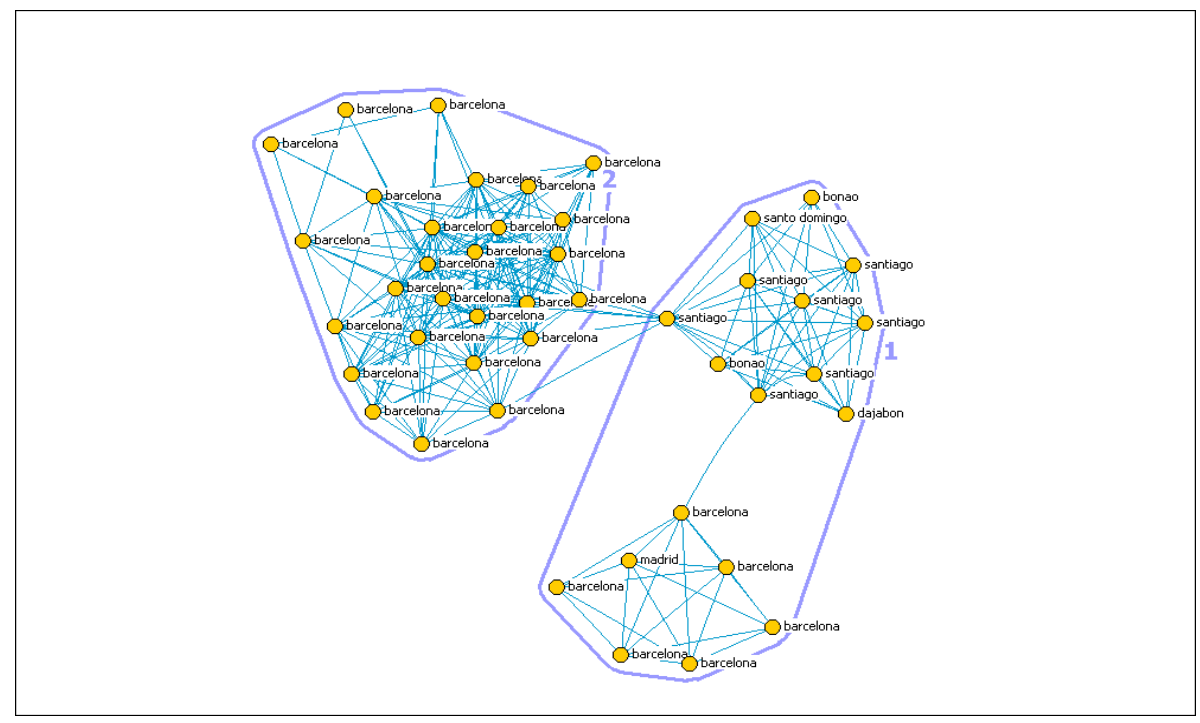

Gráfico 3. Micro-estructura Bipolar

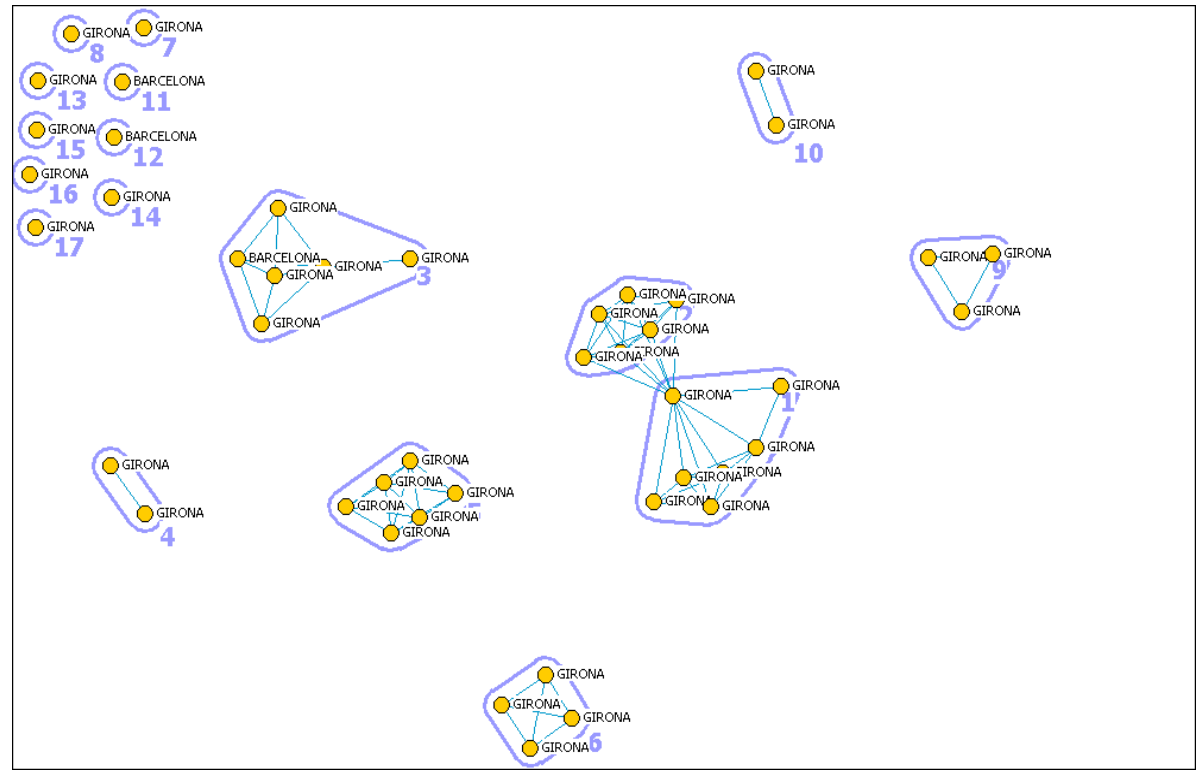

Gráfico 4. Micro-estructura segmentada

En la investigación hemos encontrado que la estructura más común en las redes personales de los inmigrantes es la "concentrada". Este tipo de estructura se desarrolla en el $47 \%$ de los casos analizados, tal como se puede apreciar en las cifras del siguiente cuadro:

\begin{tabular}{|l|c|c|}
\hline \multicolumn{1}{|c|}{ Tipo de redes } & \% & Cantidad \\
\hline Concentradas & 47 & 132 \\
\hline Bipolares & 26 & 72 \\
\hline Segmentadas & 27 & 74 \\
\hline Total & 100 & 278 \\
\hline
\end{tabular}

Cuadro 1. Estructura de clusters en redes personales inmigrantes 


\section{b. Composición étnica}

El inmigrante tiene la posibilidad de reconstruir sus redes con alteri de diversas procedencias nacionales. Entre estas opciones están: a) connacionales en la sociedad de destino, b) connacionales en la sociedad de origen, c) originarios de la sociedad de acogida y d) inmigrantes de otras nacionalidades.

La composición nacional, o étnica, de los miembros de la nueva red de ego, ofrece información importante sobre su proceso real de integración en la sociedad receptora. Por lo general, este proceso se ha estudiado a partir de los discursos desarrollados por los inmigrantes. En nuestro caso, preferimos hacerlo desde sus prácticas reales de interacción.

Estas prácticas de sociabilidad se pueden desarrollar con alteri de la misma procedencia nacional de ego o también con alteri de otras procedencias nacionales. Desde el punto de vista de ego, las prácticas desarrolladas con sus connacionales, serán culturalmente homogéneas; mientras que las desarrolladas con alteri de otras nacionalidades (fundamentalmente, originarios de la sociedad de acogida), serán culturalmente heterogéneas.

Para identificar los diferentes niveles de composición étnica hemos construido tres indicadores: a) composición homogénea, b) composición heterogeneidad baja y c) composición heterogeneidad alta. Cada indicador se calcula con el número de alteri de la misma nacionalidad de origen de ego, tomando en cuenta el siguiente criterio:

- de 30 a 45 alteri connacionales: composición homogénea

- de 15 a 30 alteri connacionales: composición heterogénea baja

- de 0 a 15 alteri connacionales: composición heterogénea alta

Los siguientes gráficos muestran ejemplos reales de los tres casos de composición étnica diferenciada. Los alteri de la misma nacionalidad de ego se representan en forma circular y color naranja, y de otras nacionalidades en forma cuadrada y color negro. 


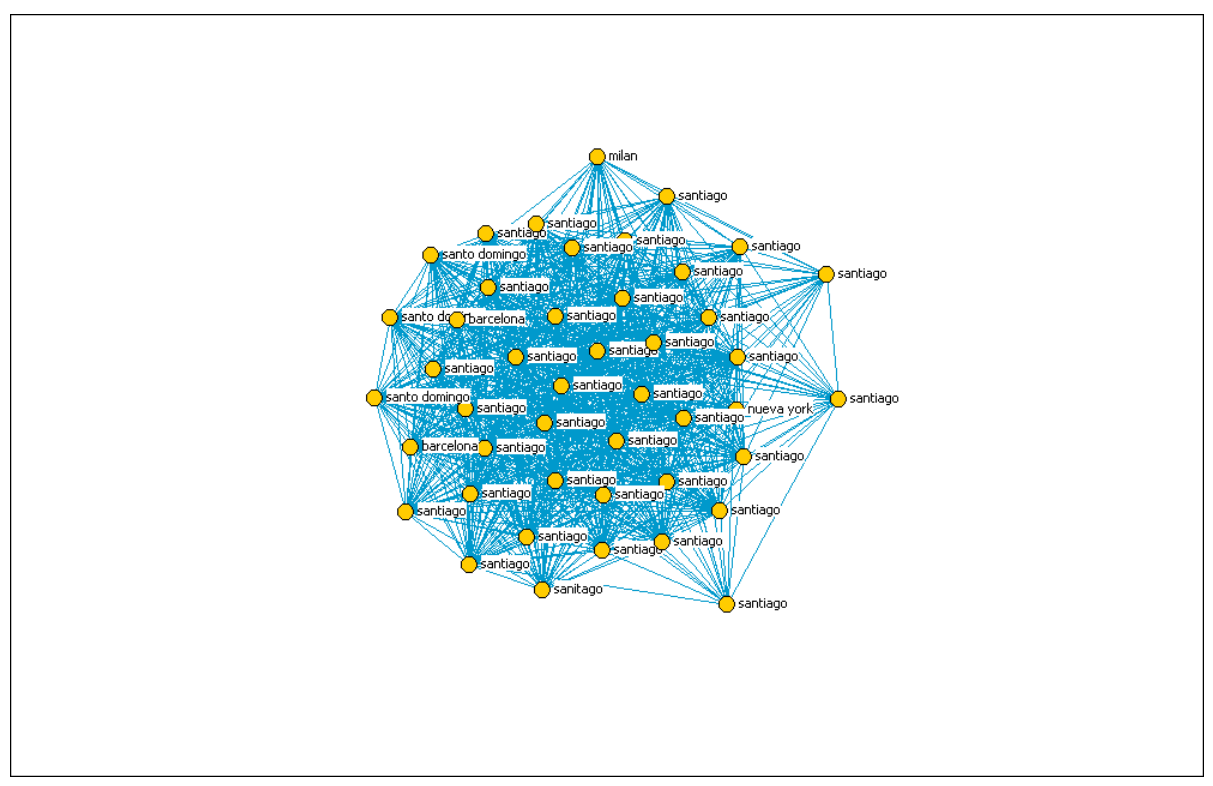

Gráfico 5. Composición homogénea

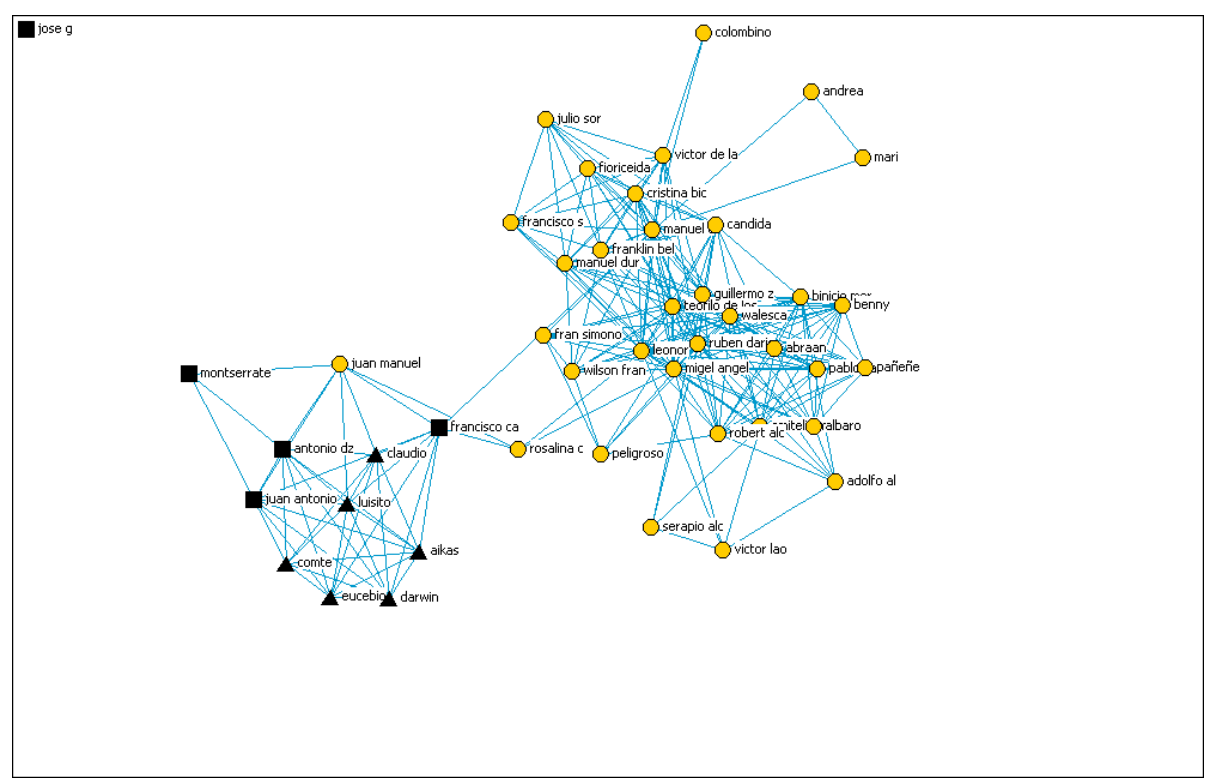

Gráfico 6. Composición con heterogeneidad baja 


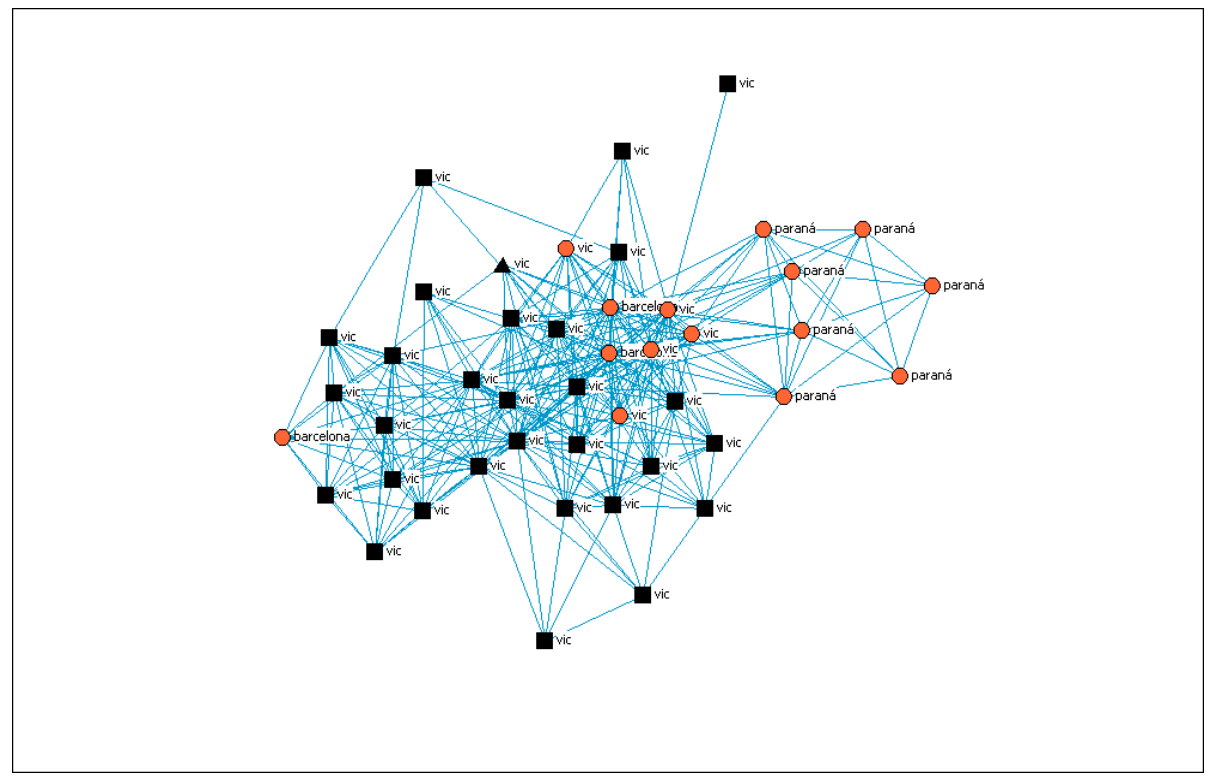

Gráfico 7. Composición con heterogeneidad alta

En la investigación hemos encontrado que el tipo de composición étnica más común es la homogénea. Este tipo de composición se desarrolla en el $49 \%$ de los casos, tal como se puede apreciar en el siguiente cuadro:

\begin{tabular}{|l|c|c|}
\hline \multicolumn{1}{|c|}{ Composición } & $\%$ & Cantidad \\
\hline Homogénea & 49 & 137 \\
\hline Heterogeneidad baja & 28 & 78 \\
\hline Heterogeneidad alta & 23 & 63 \\
\hline \multicolumn{1}{|c|}{ Total } & 100 & 278 \\
\hline
\end{tabular}

Cuadro 2. Composición étnica de las redes

\section{c. Estructura de cluster y composición étnica}

Hemos observado con detalle los indicadores de la estructura de cluster y la composición étnica. La pregunta ahora es ¿Existe relación entre la estructura de cluster y la composición étnica en las redes personales de los inmigrantes?

En nuestra investigación hemos encontrado que si. Esta relación sería positiva entre la estructura concentrada con la composición homogénea (59\%, siendo el promedio $49 \%$ ) y entre la estructura segmentada con la composición heterogénea alta (30\%, siendo el promedio $23 \%$ ). Esto significa que existiría una tendencia a que las redes de estructura concentrada tengan una composición más homogénea y las redes de estructura segmentada una composición más heterogénea. En el siguiente cuadro se pueden apreciar estas cifras con mayor detalle. 


\begin{tabular}{|l|c|c|c|c|}
\hline & \multicolumn{3}{|c|}{$\%$ Composición } & \\
\hline Estructura & Homogénea & $\begin{array}{c}\text { Heterogeneidad } \\
\text { Baja }\end{array}$ & $\begin{array}{c}\text { Heterogeneidad } \\
\text { Alta }\end{array}$ & Total \\
\hline Concentrada & 59 & 24 & 17 & 100 \\
\hline Bipolar & 47 & 28 & 25 & 100 \\
\hline Segmentada & 35 & 35 & 30 & 100 \\
\hline \multicolumn{1}{|c|}{ Total } & 49 & 28 & 23 & 100 \\
\hline
\end{tabular}

Cuadro 3. Composición y estructura de red. $\mathrm{N}=278$

¿Qué ocurre con las redes bipolares? Como se aprecia en el cuadro, este tipo de redes tienen una suerte de ubicación "intermedia" entre los extremos de la homogeneidad de las redes concentradas y la heterogeneidad alta de las redes segmentadas. El siguiente modelo representa esta relación entre la estructura de cluster y composición étnica en las redes personales de los inmigrantes:

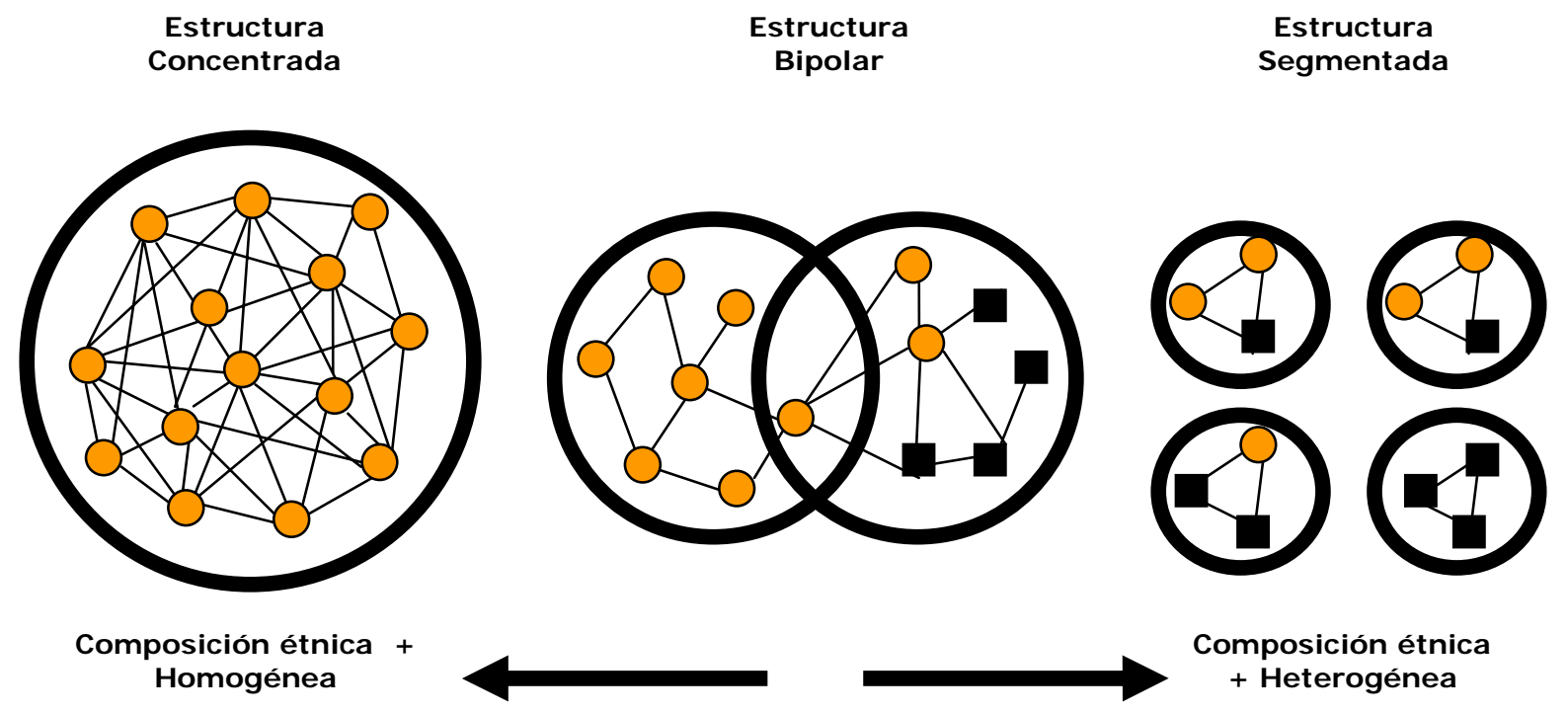

Gráfico 8. Estructuras de cluster y composición étnica redes personales inmigrantes

¿Qué relación existe entre la estructura y composición de las redes personales de los inmigrantes con sus procesos de integración en la sociedad de destino? Sostenemos que estas variables permiten identificar, con detalle, dos tipos diferentes de estrategias de integración en la sociedad receptora: a) la estrategia del "enclave étnico" y b) la estrategia de la "asimilación dispersa". 
La estrategia de "enclave étnico" tiene su expresión reticular en las estructuras concentradas y composición homogénea. Este tipo de redes suelen brindar fuerte apoyo social al inmigrante, aunque también lo segregan respecto a la sociedad receptora.

Por su parte, la estrategia de "asimilación dispersa" tiene su expresión reticular en las estructuras segmentadas y composición heterogénea. En este caso, este tipo de redes ofrece al inmigrante un tipo de capital social más funcional para su movilidad social en la sociedad receptora.

Una rápida comparación entre ambas estrategias nos mostraría que la de "enclave étnico" se caracteriza no sólo por el desarrollo de redes concentradas y homogéneas, sino también por sus contenidos polivalentes; mientras que la de "asimilación dispersa" se caracteriza por vínculos con contenidos más especializados. Del mismo modo, en el primer caso, los inmigrantes se caracterizan por desarrollar una sociabilidad de tipo más comunitarista; mientras en el segundo por una sociabilidad de tipo más individualista. Finalmente, a nivel más simbólico, en el primer caso los inmigrantes se caracterizan por desarrollar pequeños guettos de "cultura originaria"; mientras en el segundo por su hibridación y/o asimilación con la cultura de la sociedad receptora.

Ahora bien ¿Qué ocurre con las estructuras bipolares? Como veremos más adelante, esta micro-estructura se caracteriza por su ubicación intermedia entre los dos extremos que hemos analizado y se desarrolla entre las tensiones de la segregación del enclave étnico y la integración de la asimilación segmentada.

\section{I dentificando los procesos de integración de los colectivos inmigrantes en Cataluña, España.}

Líneas atrás hemos adelantado que la estructura y composición más común entre las redes de los inmigrantes es la "concentrada" ( $47 \%$ de los casos) y "homogénea" ( $49 \%$ de los casos). Sin embargo, se trata de cifras generales, que no identifican su distribución entre los cuatro colectivos inmigrantes analizados: a) Argentina, b) República Dominicana, c) Marruecos y d) Senegal/Gambia. La pregunta es ¿Existe alguna relación entre la nacionalidad de los inmigrantes y la distribución de la estructura y composición de sus redes personales? En la investigación hemos encontrado una respuesta afirmativa. 
En el caso de los indicadores de estructura de cluster, hemos encontrado que en el colectivo argentino hay un ligero predominio de las estructuras segmentadas $(42 \%)$, a diferencia de los otros tres colectivos, en donde hay un predominio de las estructuras concentradas. Sin embargo, entre estos últimos, se puede apreciar una diferencia en el caso dominicano (41\%) frente a los colectivos africanos de Marruecos y Senegal/Gambia, donde este tipo de estructura se desarrolla en el $60 \%$ de los casos, respectivamente. El siguiente cuadro presenta estas cifras con detalle.

\begin{tabular}{|l|c|c|c|c|}
\hline & \multicolumn{3}{|c|}{ \% Estructura Cluster } & \\
\hline Nacionalidad & Concentrada & Bipolar & Segmentada & Total \\
\hline Argentina & 31 & 27 & 42 & 100 \\
\hline República Dominicana & 41 & 35 & 24 & 100 \\
\hline Marruecos & 60 & 18 & 22 & 100 \\
\hline Senegal \& Gambia & 60 & 24 & 15 & 100 \\
\hline \multicolumn{1}{|c|}{ Total } & 47 & 26 & 27 & 100 \\
\hline
\end{tabular}

Cuadro 4. Estructura cluster y colectivos inmigrantes. $\mathrm{N}=278$

En el caso de los indicadores de composición étnica, hemos encontrado un claro predominio de la composición homogénea entre los colectivos de Senegal/Gambia (72\%), República Dominicana (71\%) y Marruecos (44\%), a diferencia, nuevamente, del caso argentino, donde los niveles de homogeneidad son bajos $(17 \%)$ y de heterogeneidad alta mayores (42\%). Estas cifras se presentan con detalle en el siguiente cuadro:

\begin{tabular}{|l|c|c|c|c|}
\hline & \multicolumn{3}{|c|}{$\%$ Composición étnica } & \\
\hline Nacionalidad & Homogénea & $\begin{array}{c}\text { Heterogeneidad } \\
\text { baja }\end{array}$ & $\begin{array}{c}\text { Heterogeneidad } \\
\text { alta }\end{array}$ & Total \\
\hline Argentina & 17 & 40 & 42 & 100 \\
\hline República Dominicana & 71 & 16 & 13 & 100 \\
\hline Marruecos & 44 & 34 & 22 & 100 \\
\hline Senegal \& Gambia & 72 & 18 & 10 & 100 \\
\hline \multicolumn{1}{|c|}{ Total } & 49 & 28 & 23 & 100 \\
\hline
\end{tabular}

Cuadro 5. Composición étnica de las redes y colectivos inmigrantes. 
Analizando comparativamente los resultados de las variables de estructura y composición de las redes personales, observamos que los inmigrantes del colectivo argentino desarrollan una mayor tendencia hacia la integración por "asimilación dispersa", mientras que los inmigrantes de los dos colectivos africanos desarrollan una mayor tendencia hacia la integración por "enclave étnico". En el caso de los dominicanos, se ubicarían en una suerte de posición intermedia entre ambos extremos, aunque con una mayor tendencia hacia la segregación.

¿Por qué encontramos estas diferencias en los procesos de integración de los colectivos analizados? En este punto de la investigación, es difícil ofrecer una respuesta satisfactoria. Sin embargo, creemos que la estructura y composición de las redes reproducirían, a nivel meso, las constricciones que a nivel macro la sociedad receptora ofrece a los diferentes colectivos inmigrantes.

Sin duda alguna, en el caso argentino, las barreras institucionales y sociales para su integración en la sociedad receptora son reducidas o nulas. En la gran mayoría de casos, se trata de una inmigración legal, o que se legaliza con facilidad. La gran mayoría de inmigrantes argentinos cuenta con el recurso de la nacionalidad europea de sus antepasados, lo cual favorece la rápida obtención de la ciudadanía europea comunitaria. De esta manera, la estructura de oportunidades para su integración es mayor.

Un panorama diferente encontraríamos entre los inmigrantes de los otros tres colectivos, que tendrían que enfrentar mayores problemas institucionales (legalidad) y sociales (exclusión y xenofobia) para integrarse en la sociedad española. En estos casos, las redes de parientes y paisanos suelen ofrecer un apoyo social necesario para la supervivencia. Sin embargo, esta situación se refuerza también por la misma acción de los inmigrantes, que a nivel micro buscan reconstruir sus redes sociales con sus connacionales, reforzando de esta manera los círculos de la segregación.

\section{4. ¿Cambian las redes personales de los inmigrantes?}

Las dinámicas del cambio en las redes personales es un terreno inexplorado en los estudios sobre migración internacional. Por lo general, al predominar el uso del concepto de redes sociales como metáfora, se suele pensar que las "redes étnicas" de los inmigrantes son, en cierta medida, "resistentes al cambio". En nuestra investigación hemos encontrado que no es así. 
Las redes de los inmigrantes se encuentran en proceso permanente de reinvención y cambio. En la segunda fase de nuestra investigación, hemos encontrado que, en el $100 \%$ de los casos, al estudiar una misma red en dos periodos de tiempo diferentes, se observan - de manera significativa- la presencia de nuevos alteri, reemplazando otros viejos.

La materia prima para nuestro análisis del cambio en las redes lo constituyen los alteri nuevos que aparecen en la segunda muestra. Estos alteri nos han permitido construir indicadores para medir la intensidad del cambio en las redes, entre los dos periodos de tiempo analizados. Estos indicadores de la variable "intensidad del cambio" quedaron constituidos de la siguiente manera:

- de 30 a 45 alteri nuevos: cambio fuerte

- de 15 a 30 alteri nuevos: cambio medio

- de 1 a 15 alteri nuevos: cambio débil

Utilizando estos indicadores encontramos que, en la gran mayoría de casos, se desarrollaron procesos de "cambio medio" (54\%) y "cambio fuerte" (39\%). Para nuestra sorpresa, los procesos de cambio débil constituyeron una clara minoría ( $7 \%)$. Estas cifras se presentan con detalle en el siguiente cuadro:

\begin{tabular}{|l|c|c|}
\hline Tipo cambio alteri & Cantidad & \% \\
\hline Alto & 24 & 39 \\
\hline Medio & 33 & 54 \\
\hline Bajo Total & 4 & 7 \\
\hline \multicolumn{2}{|c|}{61} & 100 \\
\hline
\end{tabular}

Cuadro 6. Tipo de cambio de alteri redes personales inmigrantes

Habiendo identificado los diferentes niveles del cambio en las redes, nuestra siguiente preocupación fue analizar la influencia de esta variable en el cambio en la estructura de cluster de las redes personales de los inmigrantes ¿Existe alguna relación entre el cambio de alteri con el cambio en la estructura de clusters? En términos generales, hemos logrado identificar que en el $43 \%$ de los casos si se produce una relación positiva entre cambios de alteri y cambios en la estructura de cluster; mientras que en el $57 \%$ restante no se produce cambio en la estructura. Es decir, las estructuras de cluster tendrían un mayor nivel de estabilidad ante el cambio de sus alteri. 
Sin embargo, nos interesaba saber si esta "estabilidad" era igual con respecto a los tres niveles de cambio que habíamos logrado identificar: a) cambio fuerte, b) cambio medio y c) cambio débil. Al hacer la comparación entre estas variables, encontramos una relación alta entre el cambio fuerte de alteri con el cambio de estructura $(63 \%)$ y una relación baja entre el cambio medio con el cambio de estructura (37\%). Lo interesante fue constatar, en el caso del cambio débil, que prácticamente en ninguno de los casos se producía cambio de estructura. Esto demostraría una relación entre el nivel del cambo alto de alteri con el cambio de estructura ${ }^{10}$.

\begin{tabular}{|l|c|c|c|}
\hline Tipo de cambio & Si cambió & No cambió & Total \\
\hline Fuerte & 63 & 37 & 100 \\
\hline Intermedio & 33 & 67 & 100 \\
\hline Débil & & 100 & 100 \\
\hline \multicolumn{1}{|c|}{ Total } & 43 & 57 & 100 \\
\hline
\end{tabular}

Cuadro 7. Cambio estructura y tipo de cambio

\section{Dinámicas de cambio en la estructura de las redes inmigrantes}

Al momento de iniciar la segunda fase de la investigación, nuestra hipótesis era que había una relación entre la estructura y composición de las redes personales con sus dinámicas de cambio. De manera específica, sosteníamos que las redes segmentadas y heterogéneas eran, por su naturaleza más "abierta" y "volátil", redes más proclives al cambio; mientras que las redes concentradas y homogéneas eran, también por su naturaleza "cerrada" y "densa", más proclives a la establidad. Sin embargo, los datos recogidos en la segunda fase del estudio falsaron nuestra hipótesis.

En primer lugar, encontramos que el colectivo que suponíamos iba a desarrollar menos cambios, el de Senegal/Gambia - por su estructura concentrada y composición homogénea-, fue el que desarrolló mayores porcentajes de "cambio fuerte" (56\%); mientras que el colectivo que suponíamos iba a desarrollar mayores cambios, el argentino -por su estructura segmentada y composición heterogénea-, fue el colectivo con menor nivel de cambio "cambio fuerte" $(18 \%)^{11}$.

\footnotetext{
${ }^{10}$ ¿Por qué se producen los “cambios fuertes"? En este número de la revista redes el Dr. José Luis Molina explora, de manera preliminar, sobre las razones que producen el cambio en las redes. En un próximo trabajo desarrollaremos este tema.

${ }^{11}$ Es probable que la diferencia responda a las distintas estrategias de integración desarrolladas por los colectivos. En el caso argentino, al estar más integrado en la sociedad receptora, no habría necesidad de hacer grandes cambios en sus redes personales; mientras que en el resto de colectivos, al estar menor integrados, si exista esta necesidad.
} 


\begin{tabular}{|l|c|c|c|c|}
\hline & \multicolumn{3}{|c|}{ \% Tipo cambio alteri } & \\
\hline Colectivos inmigrantes & Fuerte & Medio & Débil & Total \\
\hline Argentina & 11 & 71 & 18 & 100 \\
\hline República Dominicana & 47 & 47 & 6 & 100 \\
\hline Marruecos & 46 & 54 & 0 & 100 \\
\hline Senegal \& Gambia & 56 & 44 & 0 & 100 \\
\hline \multicolumn{1}{|c|}{ Total } & 39 & 54 & 7 & 100 \\
\hline
\end{tabular}

Cuadro 8. Tipo cambio de alteri y colectivos inmigrantes. $\mathrm{N}=61$

En segundo lugar, encontramos que el tipo de estructura más proclive al cambio era la "bipolar" y no la de tipo "segmentado". Del $100 \%$ de casos que presentaron relación positiva entre cambio de alteri y cambio de estructura de cluster, el $74 \%$ ocurrió con estructuras que originalmente eran "bipolar", tal como se aprecia en el siguiente cuadro:

\begin{tabular}{|l|c|c|c|}
\hline \multirow{2}{*}{ Estructura } & \multicolumn{2}{|c|}{ Cambio } & \\
\cline { 2 - 4 } & Si & No & Total \\
\hline Concentrada & 23 & 77 & 100 \\
\hline Bipolar & 74 & 26 & 100 \\
\hline Segmentada & 38 & 62 & 100 \\
\hline \multicolumn{1}{|c|}{ Total } & 43 & 57 & 100 \\
\hline
\end{tabular}

Cuadro 9. Tipo estructura cluster y cambio. $\mathrm{N}=61$

Las cifras del cuadro muestran con claridad que la estructura de tipo "bipolar" es la más proclive al cambio. ¿Por qué motivo? Nuestra hipótesis es que la estructura "bipolar" no sólo sería una estructura intermedia entre las estructuras "concentrada" y "segmentada", sino también una fase estructural de tránsito entre las dos principales dinámicas del cambio en la estructura de los cluster: a) la “segmentación” y b) la "concentración"12.

\begin{tabular}{|l|c|c|c|}
\hline \multirow{2}{*}{ Estructura } & \multicolumn{2}{|c|}{ Tipo cambio estructura } & \\
\cline { 2 - 4 } & Concentración & Segmentación & Total \\
\hline Concentrada & - & 100 & 100 \\
\hline Bipolar & 58 & 42 & 100 \\
\hline Segmentada & 100 & - & 100 \\
\hline \multicolumn{1}{|c|}{ Total } & 54 & 46 & 100 \\
\hline
\end{tabular}

Cuadro 10. Tipo estructura cluster y tipo de cambio de estructura.

\footnotetext{
${ }^{12}$ Esta hipótesis fue desarrollada en conversación con el Dr. José Luis Molina en una conversación sobre el proyecto en Sant Cugat.
} 


\section{Proceso de segmentación}

Las estructuras concentradas y bipolares pueden desarrollar procesos de "segmentación" en sus cluster. Observemos un ejemplo de este proceso en un caso real de cambio en la red personal de un inmigrante cuya primera red tenía una estructura bipolar y su segunda una estructura segmentada. Los gráficos representan una misma red en dos periodos de tiempo diferentes. La primera red fue recogida el año 2005 y la segunda el año 2007.

Cuadro A. Red Bipolar (2005)

Cuadro B. Red Segmentada (2007)
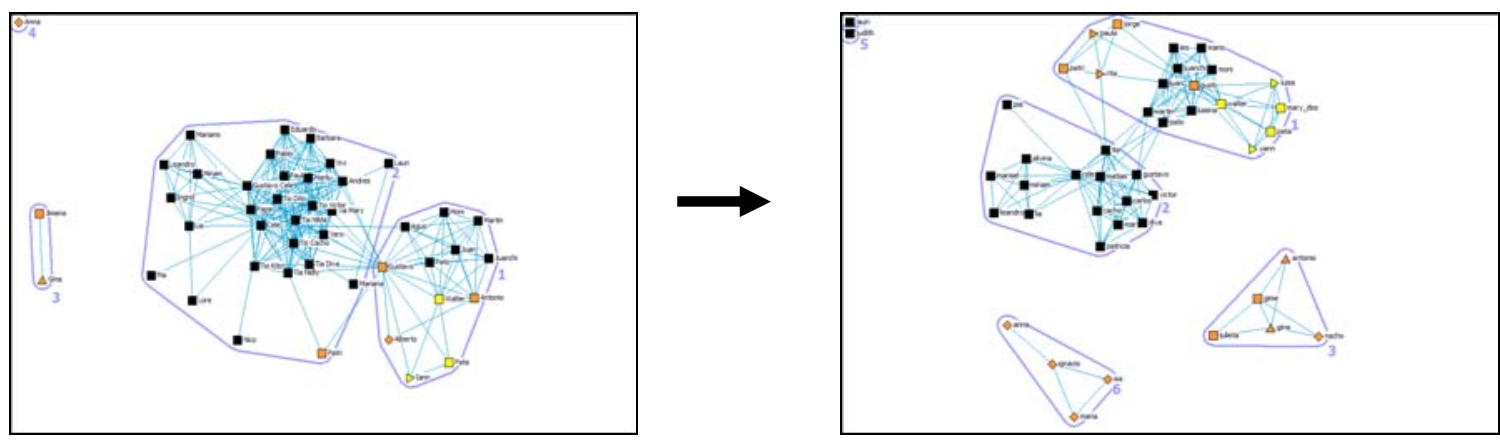

Cuadro C. Alteri nuevos (2005 - 2007)

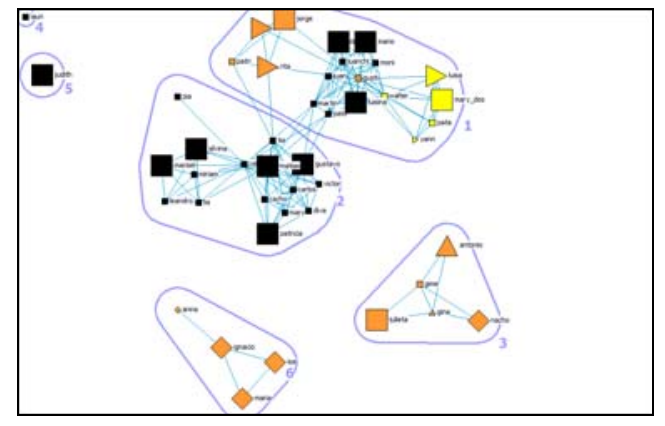

Gráfico 9. Proceso de segmentación de la red personal de un inmigrante.

En este ejemplo los alteri de la red que radican en la sociedad de origen se representan en color naranja negro y los alteri en la sociedad receptora se representan en color negro. El cuadro " $A$ " presenta la estructura bipolar de la red el año 2005 y el cuadro "B" su nueva estructura segmentada el año 2007. En el cuadro " $\mathrm{C}$ " se representan en tamaño grande los nuevos alteri que han ingresado a esta. 
Ahora bien, más allá de la constatación del cambio de alteri y el cambio en la estructura de cluster (de bipolar a segmentada), interesa también resaltar el descubrimiento de un fenómeno poco advertido en los estudios sobre redes sociales con población inmigrante: el cambio simultáneo de alteri tanto en la sociedad de destino (representado en color naranja), como en la de origen (representado en color negro). Este fenómeno se denomina en el campo de los estudios migratorios "transnacionalismo".

\section{Proceso de concentración}

Las estructuras segmentadas y bipolares pueden desarrollar procesos de "concentración" en sus cluster. Observemos otro ejemplo de este proceso, con la red de otro inmigrante que también fue estudiada en dos momentos, entre los años 2005 y 2007. En este caso, en el cuadro “D” se puede apreciar como la estructura de cluster era segmentada el año 2005, conformada por cinco grandes clusters -y varios alteri en pareja y aislados-. Luego, en el cuadro "E", se puede apreciar como esta misma red se vuelve "bipolar", mas concentrada, y articula muchos alteri que antes estaban aislados.

Cuadro D. Red Segmentada (2006)

Cuadro E. Red Concentrada (2007)

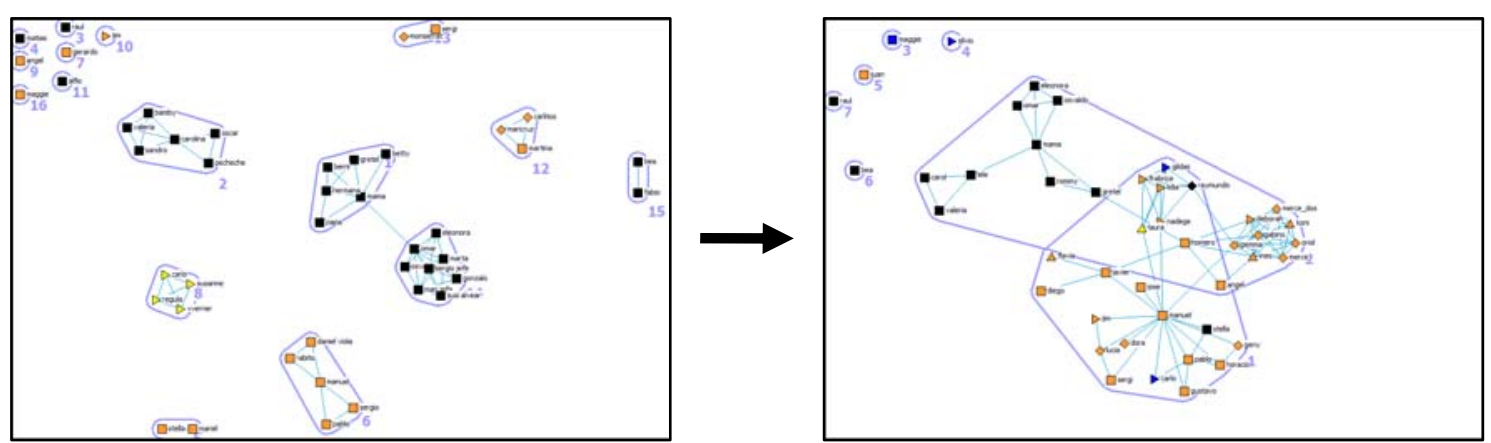

Cuadro F. Alteri nuevos (2006 - 2007)

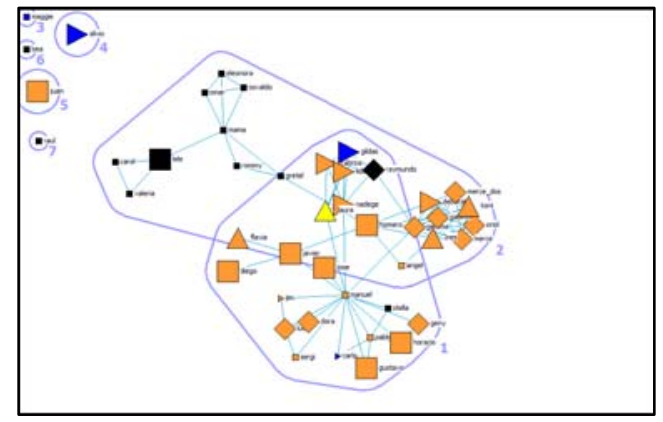

Gráfico 10. Proceso de concentración de la red personal de un inmigrante. 
Nuevamente se aprecia como cambios en los alteri de la red producen cambios en la estructura originaria. En este caso se aprecia como los nuevos alteri provienen fundamentalmente del ámbito de la sociedad de destino.

\section{Cambios en estructura y composición de la red personal}

En las redes personales de los inmigrantes existe una relación entre la estructura de cluster y su composición étnica. En las dinámicas de cambio también. Es decir, un proceso de "concentración" de cluster suele ir acompañado de otro de “homogenización" en la composición de sus miembros; mientras que un proceso de "segmentación" de cluster suele ir acompañado de otro de "heterogenización" en la composición de sus miembros. El siguiente modelo representa la dinámica de estos procesos de "segmentación" y "concentración" en las redes personales de los inmigrantes. Es interesante advertir que las redes de estructura bipolar tendrían una ubicación de "transito" intermedio entre los extremos de las redes concentradas de un lado y las redes segmentadas de otro lado.

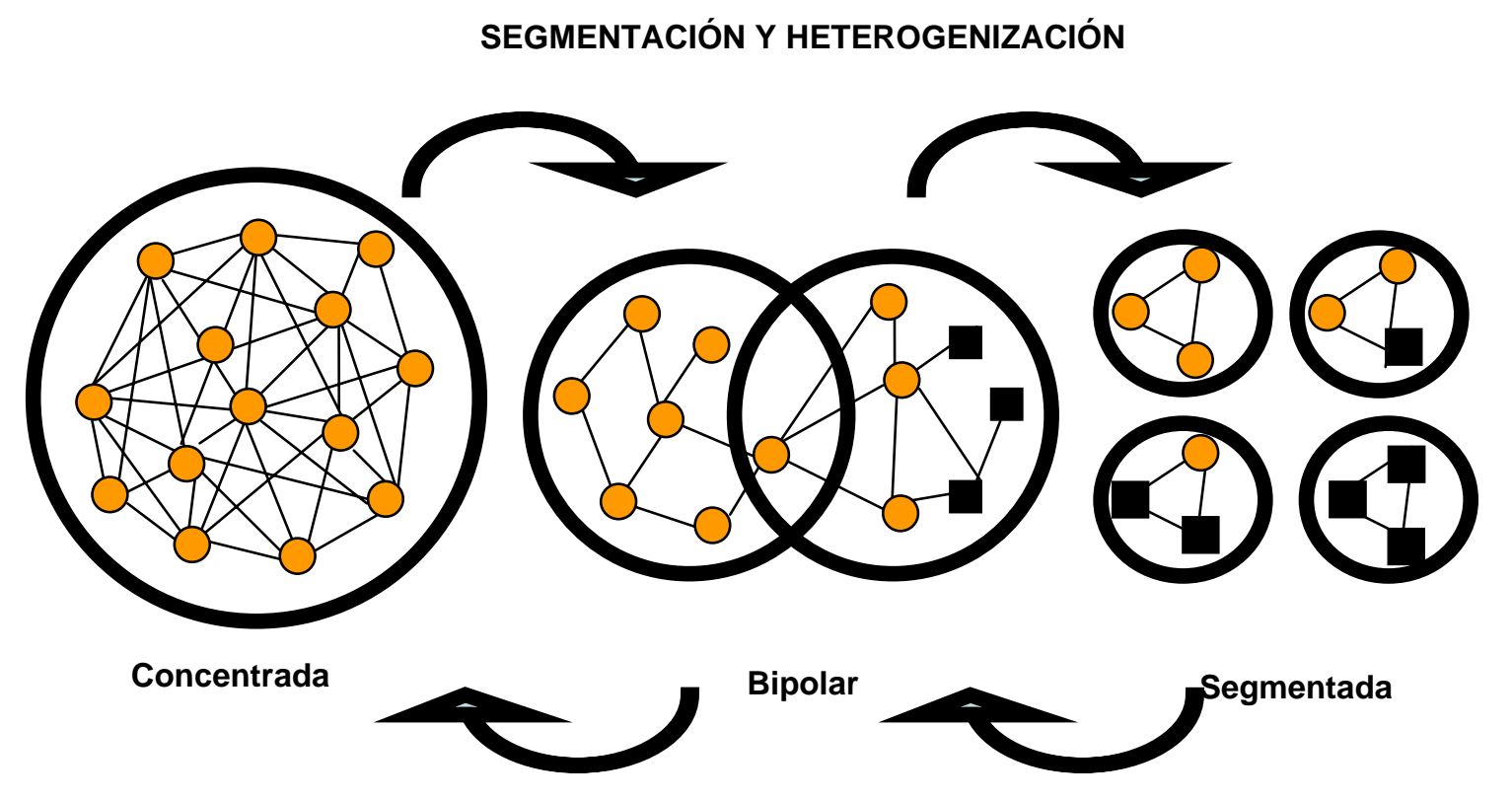

CONCENTRACIÓN Y HOMOGENIZACIÓN

Gráfico 11. Modelo dinámico de cambio de las redes personales de los inmigrantes.

¿Cómo se desarrollan estas dinámicas de concentración y segmentación? Desde nuestra perspectiva, esta evidencia requiere repensar el ámbito de análisis de estas redes, incorporando contextos "locales" y "no-locales". Es decir, transnacionales. 


\section{Dinámicas transnacionales}

¿Cómo explicar estas dinámicas de "concentración" y "segmentación" en las redes personales de los inmigrantes? Sin duda, una parte de la respuesta se encuentra en las estrategias que desarrollan los inmigrantes para su integración en la sociedad receptora. Sin embargo, como se pudo apreciar en los dos ejemplos de cambio estructural, la otra parte de la respuesta se tiene que buscar en la sociedad de origen de estos inmigrantes. ¿Por qué razón? En lo fundamental, porque las redes personales de los inmigrantes desarrollan, en la gran mayoría de casos, una condición que en el campo de los estudios sobre migración internacional se define como "transnacional". Es decir, redes que el inmigrante mantiene activas, desde la sociedad de destino, con alteri residentes en su sociedad de origen.

El concepto de transnacionalismo puede verse como lo contrario de la noción “canónica" de asimilación ${ }^{13}$ como proceso gradual pero irreversible de aculturación e integración de los migrantes a la sociedad receptora. En vez de eso, el transnacionalismo evocaría la imagen de un movimiento imparable de ida y venida entre países receptores y de origen, permitiéndole a los migrantes sostener una presencia en ambas sociedades y ambas culturas y explotar las oportunidades económicas y políticas creadas por tales vidas duales.

Para Alejandro Portes (Portes, 2004) el descubrimiento de prácticas transnacionales por parte del grupo de antropólogas conducidos por Nina Glick Schiller, Cristina Blanc-Szanton y Linda Basch ha generado un nuevo campo de debate en los estudios sobre migración internacional, definiendo el transnacionalismo como el proceso por el cual los transmigrantes, a través de su actividad cotidiana, forjan y sostienen relaciones sociales, económicas y políticas "multilineales" que vinculan sus sociedades de origen con las de asentamiento y a través de las cuales crean campos transnacionales que atraviesan las fronteras nacionales. (Glick Schiller, 1992)

\footnotetext{
${ }^{13}$ Desde la perspectiva asimilacionista, el inmigrante desarrollaba un proceso de "integración progresiva" en las estructuras económicas, políticas, sociales y culturales de la sociedad receptora. La "direccionalidad" de este proceso ni siquiera se sometía a debate, ya que se suponía que la migración había sido resultado de la confluencia entre factores de expulsión (push) en la sociedad originaria y atracción (pull) en la sociedad de destino. Por el contrario, el debate se enfocaba en la identificación de factores que facilitaban o dificultaban la "asimilación" de los inmigrantes en las estructuras de la sociedad receptora (Guarnizo y Portes, 2003). De esta manera, la "velocidad" con la cual el inmigrante "dejaba atrás" sus vínculos y valores culturales originarios, era un indicador que permitía medir sus niveles de integración en la sociedad receptora. Desde esta perspectiva, los "viejos" vínculos sociales y valores culturales, serían reemplazos por otros "nuevos", procedentes de la sociedad de destino. Fue desde estas premisas generales que J.W. Berry elaboró su conocido modelo sobre la "aculturación inmigrante", el cual ofrecía cuatro alternativas para la integración del inmigrante en la sociedad receptora: a) asimilación, b) pluralismo, c) segregación o d) exclusión (Berry, 1997).
} 
En la actualidad, las evidencias empíricas sobre el desarrollo de este fenómeno son mayores, lo cual ha implicado una importante redefinición en las teorías sobre la asimilación e integración de los inmigrantes en la sociedad de destino, y ha puesto en debate el canon sobre "la inevitable" asimilación de los inmigrantes en la sociedad receptora.

Una de las fortalezas de la perspectiva teórica del transnacionalismo es que permite ver el proceso tomando en cuenta los dos contextos donde se desarrollan las vidas de algunos inmigrantes, como son la sociedad receptora, pero también la sociedad de origen. En ese sentido, fenómenos como la segregación e inclusive la marginación del inmigrante respecto a la sociedad receptora, pueden ser indicadores del desarrollo de otros tipos de procesos, de carácter más bien transnacional, entre el inmigrante y su sociedad de origen ${ }^{14}$.

Todavía no conocemos bien la relación entre la condición transnacional con el desarrollo de las estructura y composición de las redes personales de los inmigrantes. Sin embargo, por ahora sabemos que no se trata de un fenómeno menor, sino más bien masivo, en la conformación de las nuevas redes sociales de los inmigrantes. En nuestro estudio, hemos encontrado que el $92 \%$ de las redes desarrollan una condición transnacional. Se trata, a todas luces, de un fenómeno masivo, que se desarrolla de manera transversal y equitativa entre los cuatro colectivos inmigrantes que hemos analizado, tal como se aprecia en el siguiente cuadro:

\footnotetext{
${ }^{14}$ Alejandro Portes señala que la literatura acerca de la inmigración generalmente ha supuesto que los inmigrantes, tan pronto llegan, se establecen en la sociedad receptora y emprenden un gradual pero inevitable proceso de asimilación. Y que esta literatura toma en consideración a los inmigrantes que regresan a sus países de origen, pero no los movimientos de ida y vuelta, ni los intercambios habituales de bienes tangibles e intangibles entre el lugar de origen y de destino. Estos movimientos y el campo binacional que crean gradualmente, vienen a ser una forma de adaptación alternativa para los inmigrantes en el mundo desarrollado. Mientras anteriormente, el éxito económico y el estatus social dependían en forma exclusiva de una rápida aculturación y del ingreso al ámbito dominante de los círculos de la sociedad receptora, en la actualidad éstos dependen cada vez más del cultivo de redes sociales sólidas a través de las fronteras nacionales. En palabras de Portes: "Para los inmigrantes involucrados en actividades transnacionales y sus contrapartes en el país de origen, el éxito no depende tanto de abandonar su cultura e idioma para adoptar los de otra sociedad, sino de preservar su acervo cultural original, mientras se adaptan instrumentalmente a la segunda sociedad (portes op cit)".
} 


\begin{tabular}{|l|c|c|c|}
\hline & \multicolumn{2}{|c|}{$\%$ Condición transnacional } & \\
\hline Colectivos & Transnacional & No transnacional & Total \\
\hline Argentina & 93 & 7 & 100 \\
\hline República Dominicana & 92 & 8 & 100 \\
\hline Marruecos & 88 & 12 & 100 \\
\hline Senegal \& Gambia & 94 & 6 & 100 \\
\hline \multicolumn{1}{|c|}{ Total } & 92 & 8 & 100 \\
\hline
\end{tabular}

Cuadro 11. Transnacionalismo y colectivos inmigrantes. $\mathrm{N}=278$.

Como se puede apreciar en el cuadro de arriba, la condición transnacional es una variable que se desarrolla de manera similar entre los cuatro colectivos estudiados. ¿Cuál es su relación con las variables de estructura y composición de las comunidades personales? Y ¿Cuál es su relación con los procesos de cambio en las redes personales? En este nivel de la investigación, sólo podemos enunciar estas preguntas, y señalar, a manera de hipótesis, que existe una relación entre las dinámicas del transnacionalismo, con los procesos de concentración/homogenización y segmentación/heterogenización de las comunidades personales de los inmigrantes, en donde las redes personales con estructuras concentradas y composición homogénea tienen mayores niveles de transnacionalismo, mientras que las redes con estructuras segmentadas y composición heterogénea tendrían menores niveles de transnacionalismo.

\section{Una hipótesis de trabajo}

Hemos encontrado que la gran mayoría de redes inmigrantes no sólo tienen una estructura transnacional (es decir, redes entre origen y destino), sino que las dinámicas del cambio se producen en ambos contextos, de manera simultánea.

¿Por qué se produce este fenómeno de "cambio simultáneo" en las redes ubicadas en la sociedad de origen del inmigrante y en la de destino? Para una adecuada respuesta se requiere ampliar el foco de análisis - enfocado inicialmente en torno a la sociedad de destino- e incluir también a la sociedad de origen.

¿Qué es lo que ocurre en la sociedad de origen? Hemos constatado dos cosas. Primero, las redes que el inmigrante reconstruye en destino en algún momento del proceso se vuelven hacia la sociedad de origen. $Y$ en la sociedad de origen se forman nuevas relaciones con personas que anteriormente formaban parte de su comunidad personal originaria, y también con personas nuevas que desean tener algún tipo de "vínculo estratégico" con el inmigrante en el extranjero. Este proceso se explica mejor a través de la representación gráfica de la secuencia. 
Para comprender el fenómeno, el punto de partida tiene necesariamente que situarse en el momento en que el inmigrante sale de su país de origen. En ese momento, el inmigrante, que vamos a denominar "ego", ha venido desarrollando sus procesos de sociabilidad dentro del marco de unas redes personales con una estructura y composición definida. Por lo general, en países expulsores de emigración, "ego" tiene en su red personal algún alteri en el extranjero, con el que puede tener un vínculo directo o indirecto. Normalmente estos alteri en el extranjero son los que definen el lugar de destino de "ego".

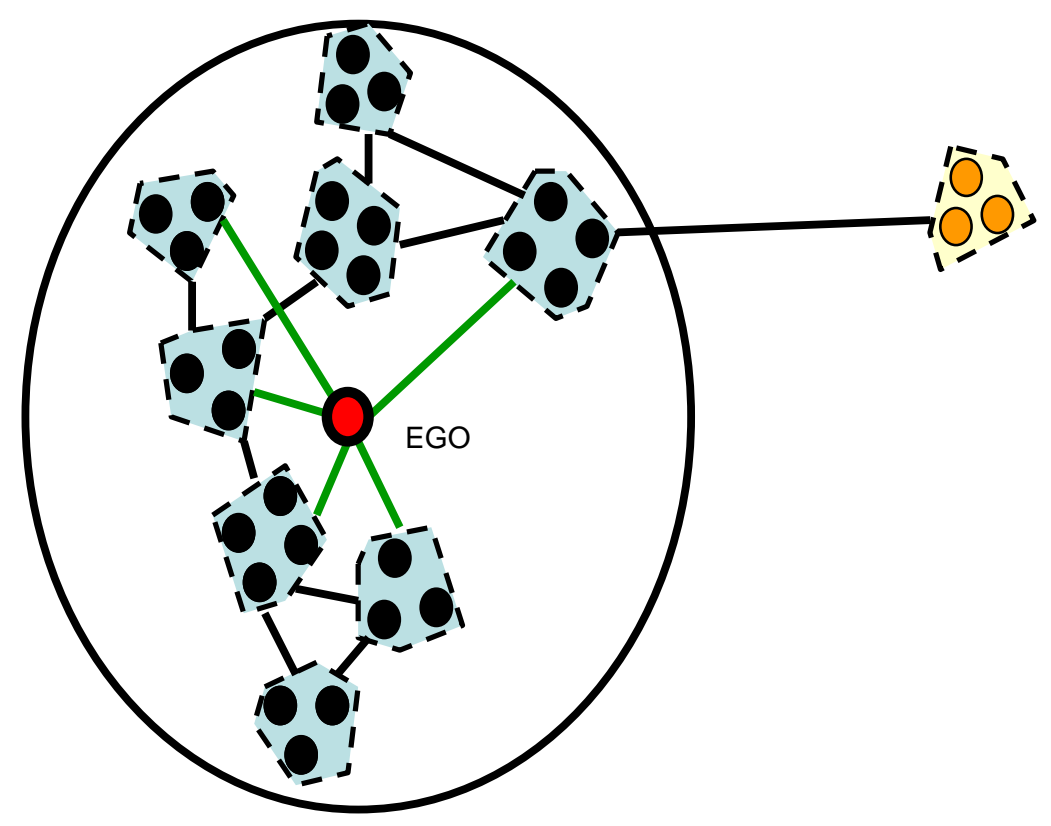

Comunidad Origen

Gráfico 12. Dinámicas trasnacionales (i).

La partida de "ego" fuera de su comunidad de origen genera la desestructuración de su red en la comunidad de origen y un proceso de reestructuración nuevo en la sociedad de destino. Este proceso se desarrolla -por lo general- teniendo como punto de partida los contactos previos que ha desarrollado antes de emigrar. 


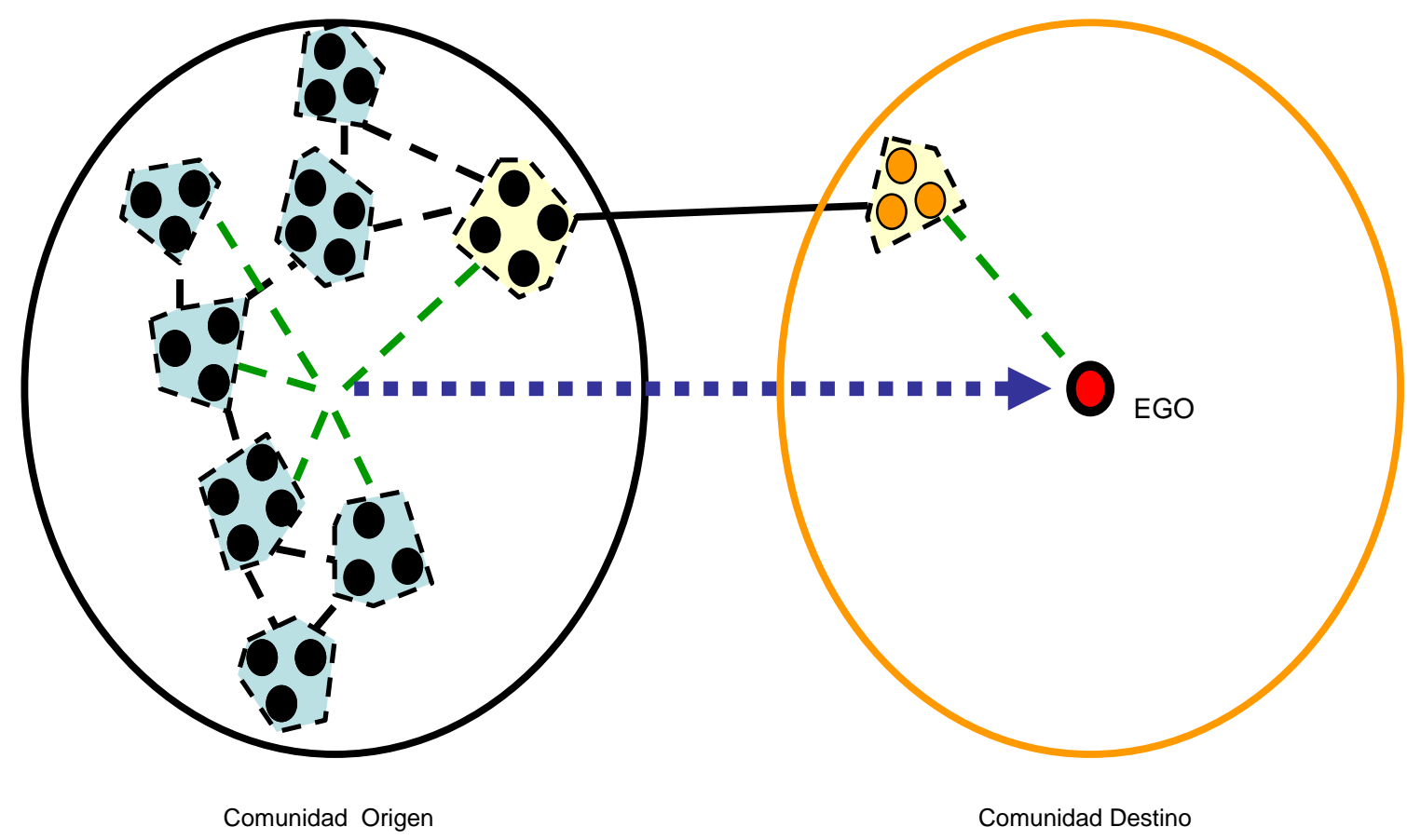

Gráfico 13. Dinámicas trasnacionales (ii).

En su primera fase, el proceso de inserción en la sociedad de destino es problemático. Aspectos legales, económicos, culturales y sociales se vuelven barreras que constriñen la libertad de sociabilidad de "ego". Por lo general, la reconstrucción de las primeras redes es con paisanos de su misma nacionalidad. En esta primera etapa, de alta precariedad para el inmigrante, los vínculos con lo que era su comunidad de origen se debilitan bastante. Es una etapa en la cual el inmigrante no esta "ni aquí ni allá". Este percibe que la distancia geográfica con origen se va volviendo también distancia social y cultural. Y también observa las dificultades para el desarrollo de una nueva sociabilidad en destino. En esta fase es normal que la estructura de las redes sea muy transnacional y segmentada, con una composición étnica homogénea. 


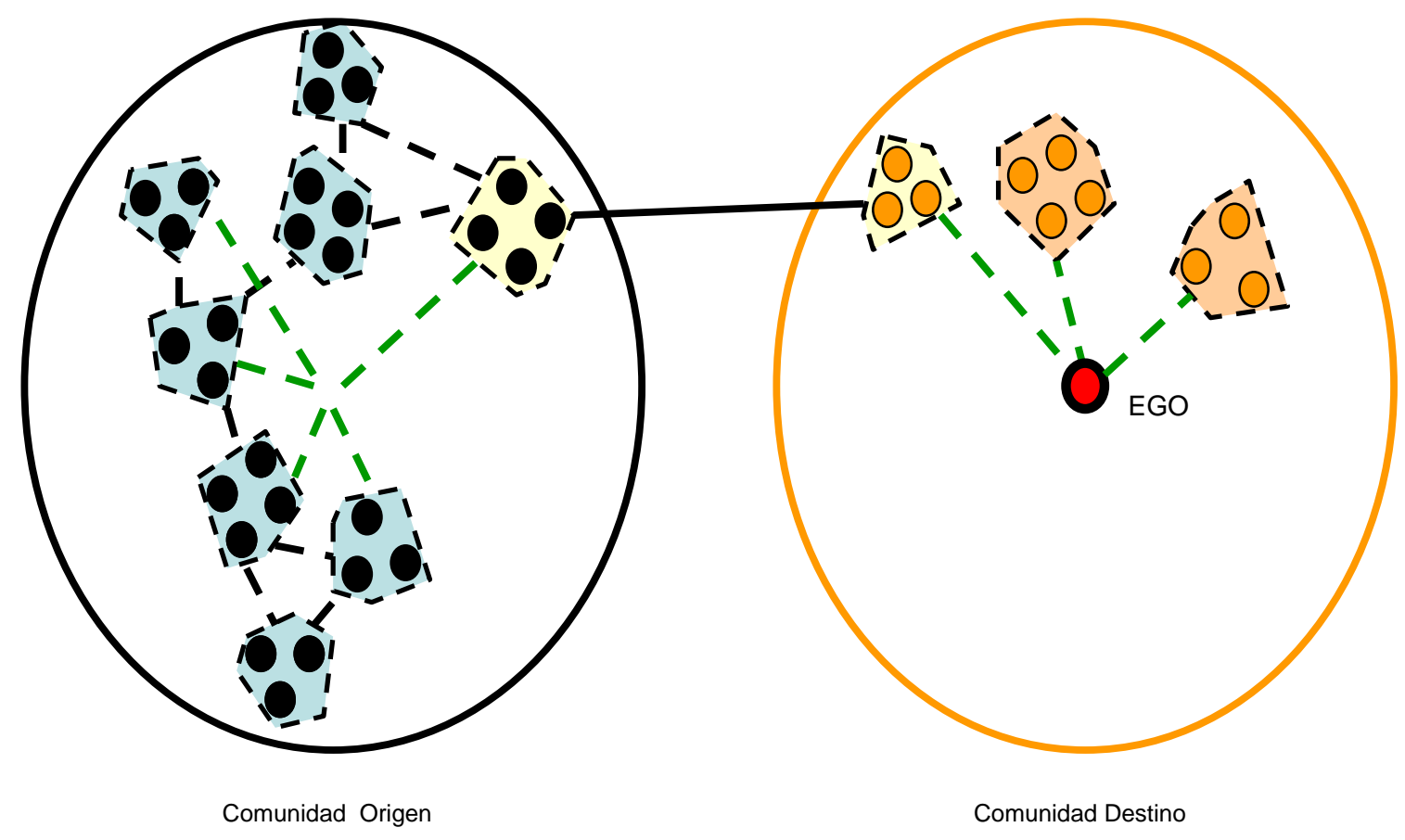

Gráfico 14. Dinámicas trasnacionales (iii).

Sin embargo, conforme el inmigrante pasa la primera fase de adaptación en destino, los vínculos con origen asumen una nueva condición. La "inercia" de las relaciones originales va disminuyendo. Ego percibe claramente que los recursos y el tiempo que tiene para mantener activas redes con origen son limitados. Se vuelve selectivo y conserva relación con las personas que considera más valiosas para el esfuerzo que implica la relación transnacional. Por lo general se trata de personas que han conformado su núcleo de redes fuertes originario, conformado por familiares directos y amigos "de toda la vida". Los compañeros de trabajo, estudios, barrio o asociaciones diversas van quedando relegados a un rol más bien pasivo.

Esto ocurre en origen cuando en destino las redes de "ego" están más consolidadas. En esta segunda fase ha logrado constituir una nueva comunidad personal es destino. Esta comunidad desarrolla una estructura y composición definidas, las que van incorporando también a personas de la sociedad de origen y extranjeros de otros países. En esta fase, "ego" ya desarrolla procesos de sociabilidad nuevos, en espacios de sociabilidad nuevos, en la sociedad de destino. En esta fase "ego" ya ha redefinido su comunidad personal. Ha desarrollado una nueva estructura de redes y una nueva cultura inmigrante. 


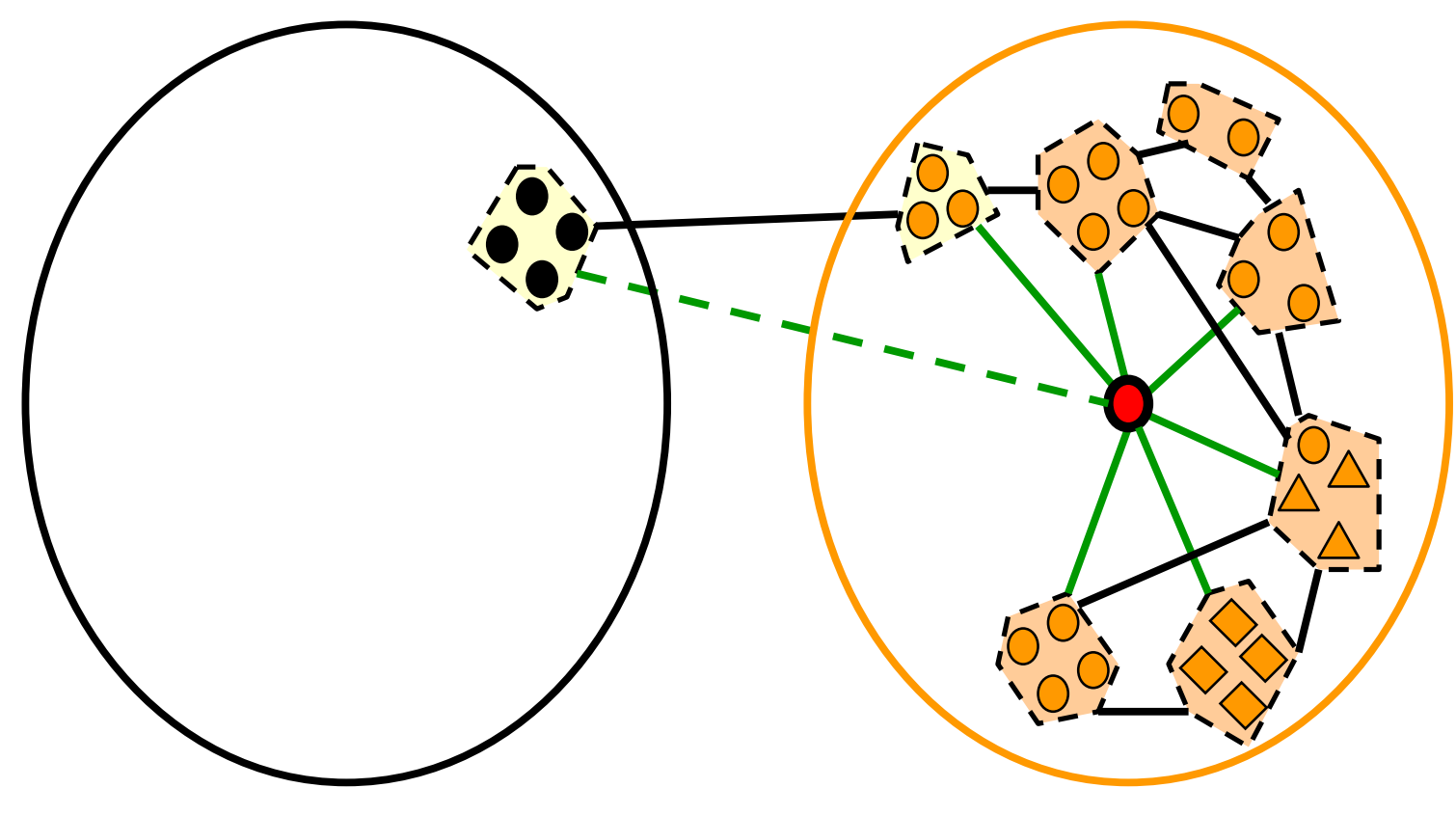

Comunidad Destino

Gráfico 15. Dinámicas trasnacionales (iv).

Las redes de "ego" en destino no son estáticas en destino sino dinámicas. Su estructura y composición varían en esta fase con inusual intensidad. Se observan procesos de concentración y segmentación en su estructura y procesos de homogenización y heterogenización en su composición.

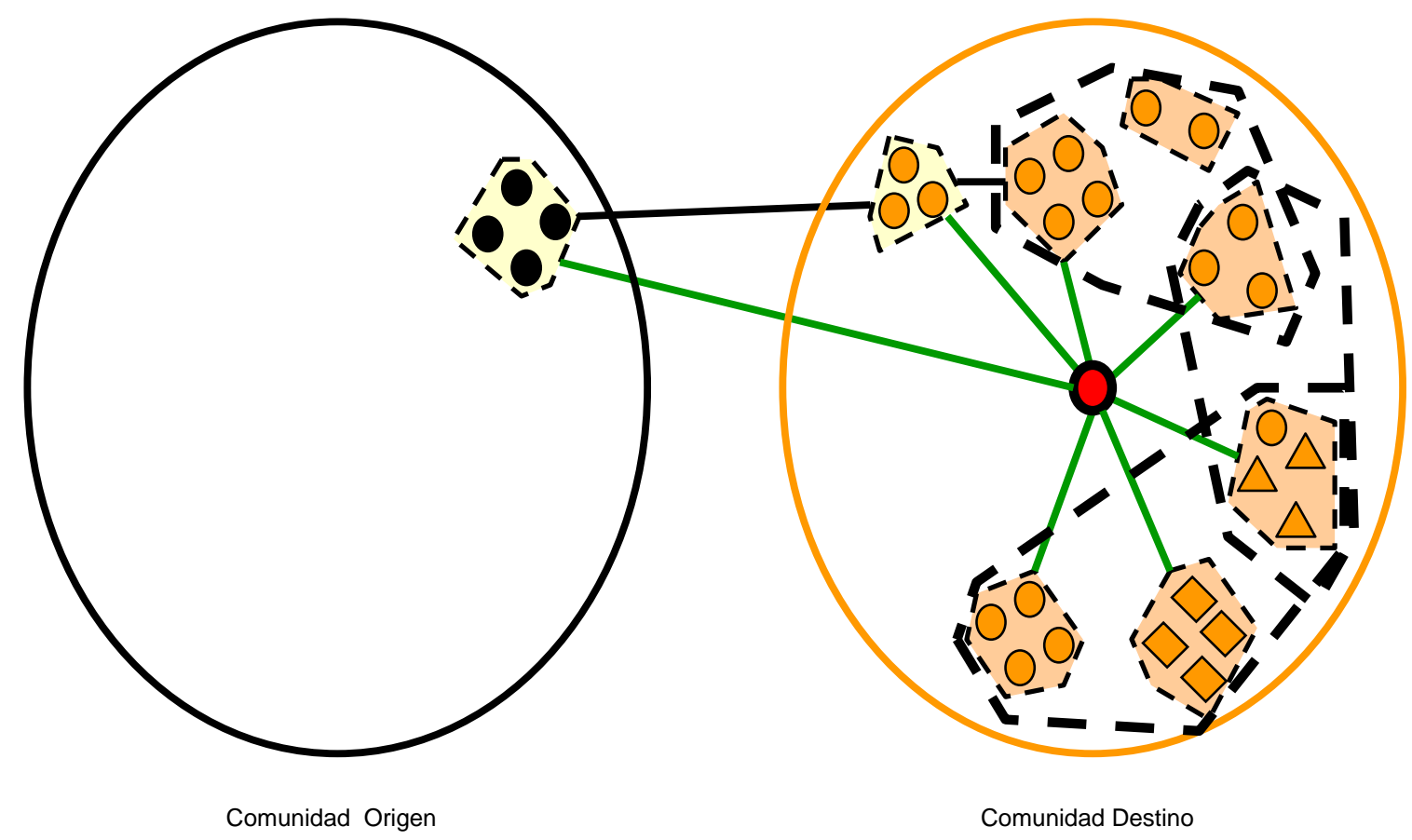

Gráfico 16. Dinámicas trasnacionales (v). 
Las relaciones entre "ego" y sus alteri en destino y origen generan la constitución de lo que se denomina "campo transnacional". Este campo tiene la peculiaridad de constituirse en función a las redes de sociabilidad que se desarrollan "ego" entre la sociedad de origen y destino.

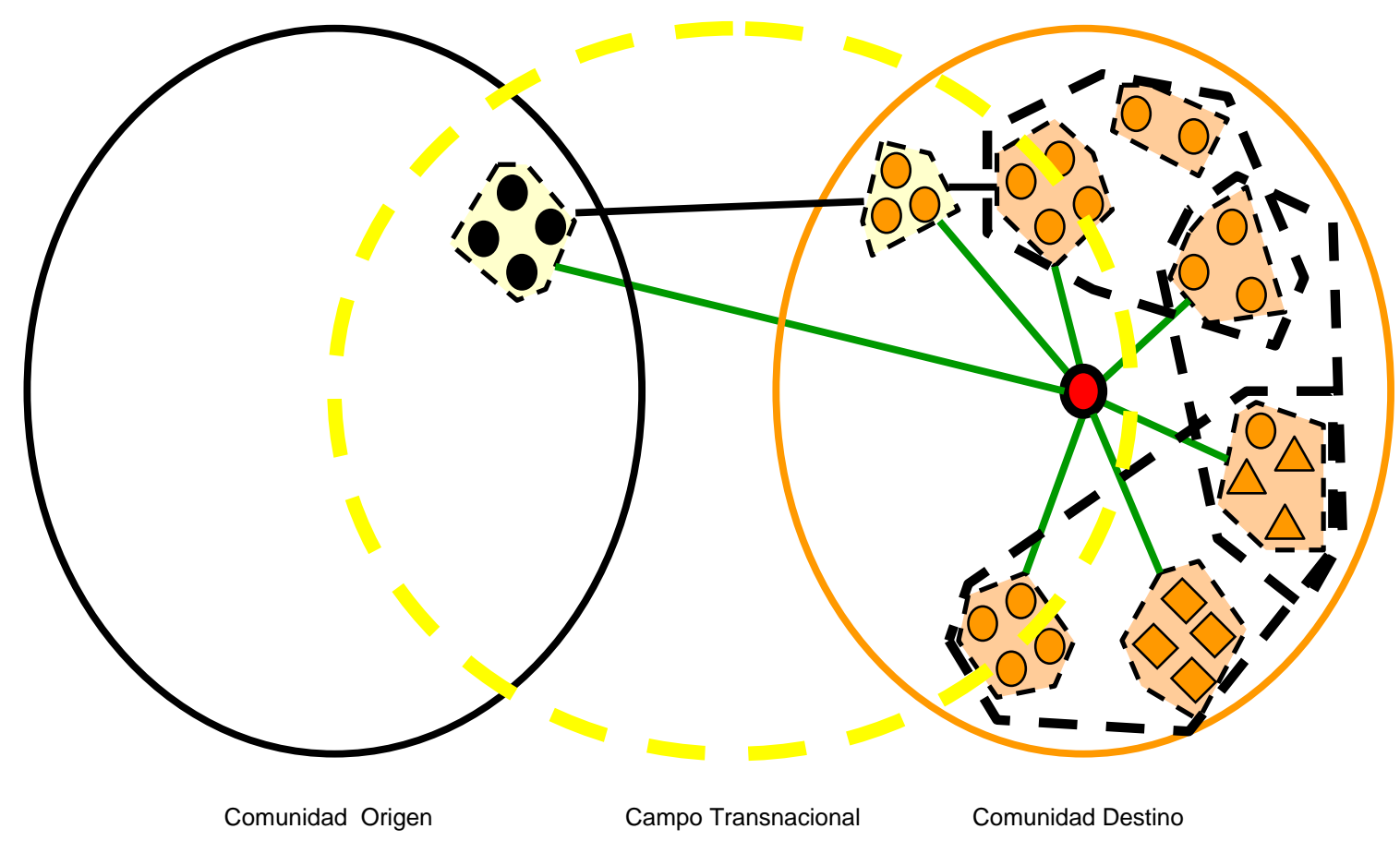

Gráfico 17. Dinámicas trasnacionales (vi).

Ahora bien, "ego" tampoco establece relaciones transnacionales "al azar" con su sociedad de origen. Lo hace con personas que formaban parte de su red antes de emigrar, espacialmente con aquellos ubicados en su núcleo, cuyos nexos se habían mantenido en estado de latencia. Los contactos que establece "ego" tienen repercusiones en origen. Este pasa a ocupar una situación de "puente" entre la comunidad local y la sociedad de destino a la cual otros quisieran también emigrar. Algunos miembros de la antigua red establecen contactos con "ego" y se incorporan dentro del campo transnacional, donde se desarrolla una nueva sociabilidad entre ellos y ego. 


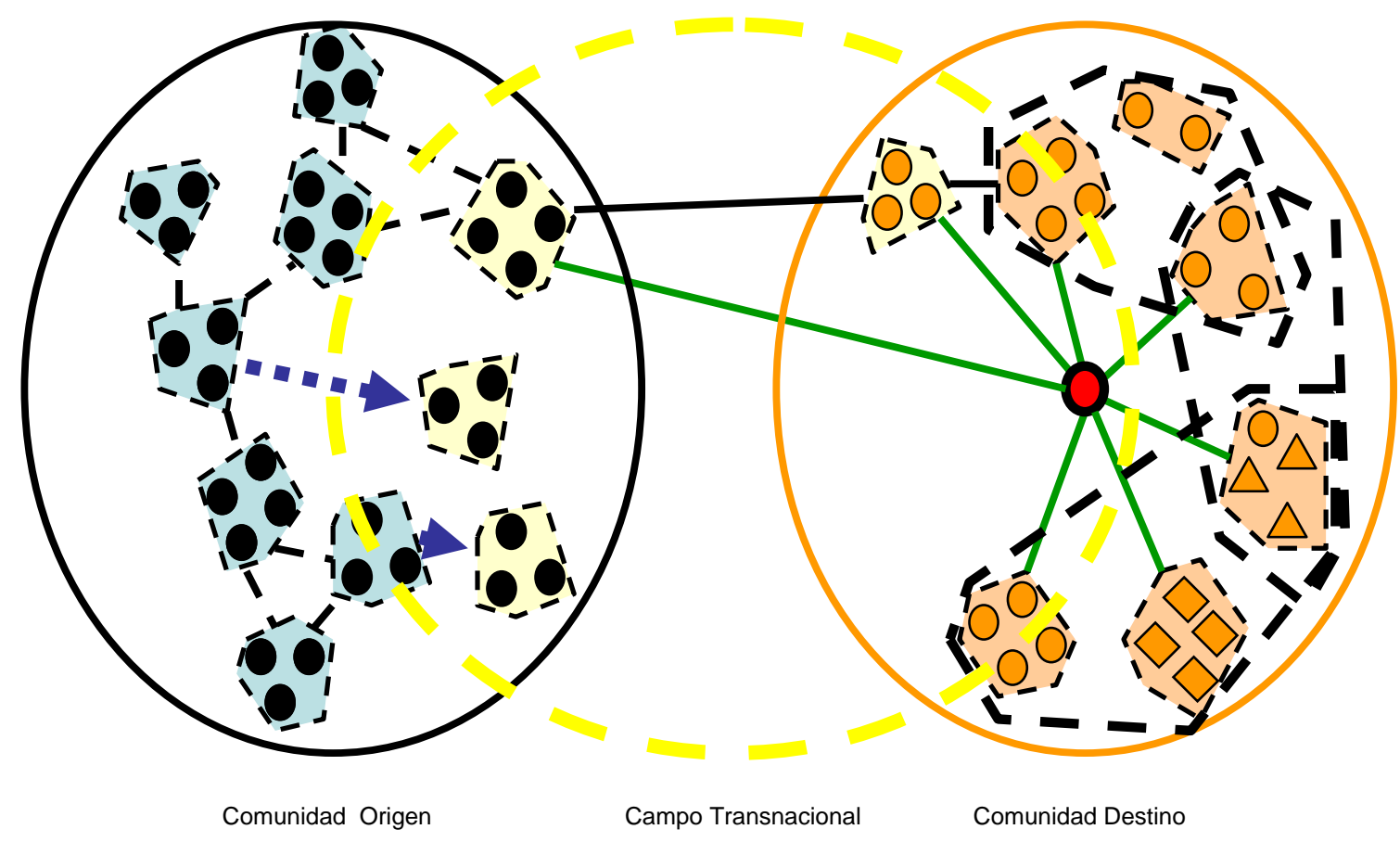

Gráfico 18. Dinámicas trasnacionales (vii).

¿Por qué cambian las redes en origen? En la mayoría de casos, la inmigración tiene un trasfondo económico. Sin embargo, se trata de un proceso que no es sólo individual sino también familiar. Los contactos que "ego" establece desde destino hacia origen son fundamentalmente para el envío de remesas y para organizar procesos de reagrupación familiar. También para facilitar información y recursos para que otros sigan la trayectoria migratoria que el ha desarrollado. Sin embargo, este proceso no sólo se desarrolla entre "ego" y su núcleo de personas más allegadas. También se desarrolla porque personas que anteriormente formaban parte de su red, ahora tienen un incentivo en reestablecer el contacto con "ego" para que sea un eslabón dentro de una cadena migratoria que los pueda ayudar a emigrar también. En estos casos, las redes en origen serían muy sensibles al desarrollo de relaciones con alteri estratégicamente ubicados en el extranjero, con quienes se buscaría constituir una cadena migratoria. 


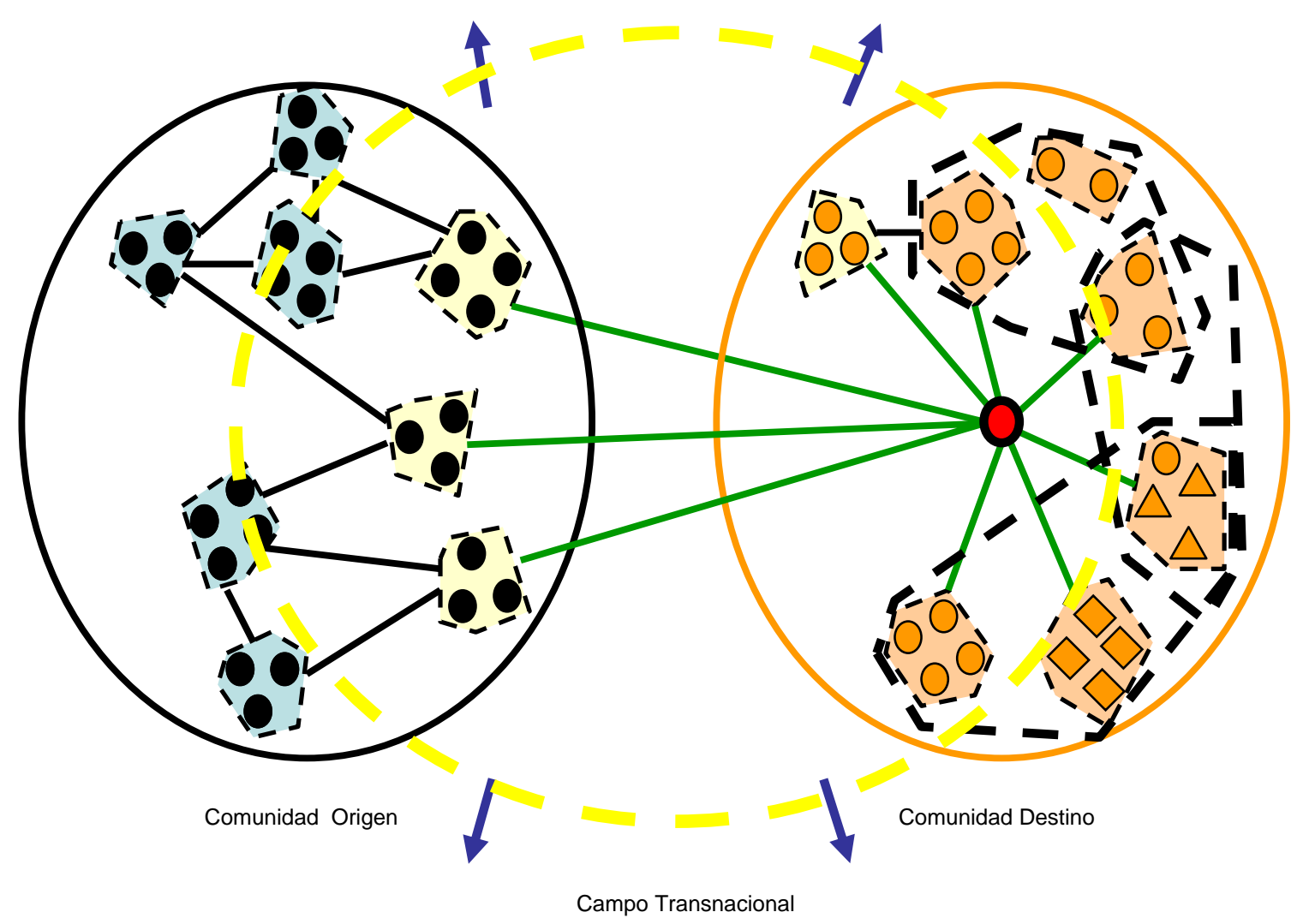

Gráfico 19. Dinámicas trasnacionales (viii).

La constatación más importante es que la migración genera impactos tanto en la sociedad receptora como en la emisora. En la receptora, el inmigrante desarrolla nuevos procesos de sociabilidad, nuevas redes e identidades que desarrollan su dinámica de integración particular. La relación entre lo "local" y "no-local" incluye en la gran mayoría de casos a redes transnacionales con sus lugares de origen. Sin embargo, en la sociedad de origen el cambio no sólo es producto de la iniciativa del inmigrante, sino también de alteri cercanos que buscan establecer un vínculo estratégico con el inmigrante, conformándose nuevas cadenas migratorias.

\section{Conclusiones}

El análisis de las redes personales de los inmigrantes nos muestra que existe una relación entre variables de su estructura y composición con los procesos de integración que desarrollan en la sociedad receptora. Estas variables son: a) estructura de cluster y b) composición étnica. 
En el caso de la estructura de cluster existen tres tipos de estructuras, que son las siguientes: a) concentradas, b) bipolares y c) segmentadas. Por su parte, en el caso de la composición étnica, existe tres niveles de homogenedidad/heterogeneidad: a) homogénea, b) heterogénea baja y c) heterogénea alta.

Existe una relación entre estas variables de estructura y composición. En el caso de las estructuras concentradas, la composición étnica suele ser homogénea; mientras que en el caso de las estructuras segmentadas, la composición étnica suele ser heterogénea. Las estructuras bipolares se ubican en una situación de heterogeneidad intermedia.

El análisis de la estructura y composición de las redes ha permitido identificar dos tipos de estrategia de integración de los inmigrantes en la sociedad receptora: a) enclave étnico y b) asimilación dispersa.

Del mismo modo, el análisis de redes ha permitido identificar que los inmigrantes argentinos desarrollan mayores procesos de segmentación y heterogeneidad; mientras que las redes de los inmigrantes dominicanos, marroquíes y senegambianos desarrollan mayores procesos de concentración y homogeneidad.

A nivel dinámico, se ha podido constatar que las redes de los inmigrantes desarrollan importantes procesos de cambio en sus alteri. Estos procesos se desarrollan en niveles de cambio fuerte y medio. Hemos podido constatar que en los casos de cambio fuerte, se desarrolla una transformación en la estructura y composición de la red del inmigrante.

Estos procesos de transformación se desarrollan de la siguiente manera: a) concentración de cluster y homogeneización de la composición étnica y b) segmentación de cluster y heterogeneización de la composición étnica.

La estructura más proclive al cambio es la bipolar. Esta estructura no sólo tendría una ubicación intermedia entre los extremos concentrado/homogéneo y segmentado/heterogéneo, sino sería también una estructura muy inestable, "de tránsito" entre ambos polos.

\section{Bibliografía}

Araya Dujisin, Rodrigo e Isidro Maya Jariego (2005). "Los puentes interlocales: las redes personales de los universitarios alcalareños en Sevilla en José I. Porras y Vicente Espinoza (eds.), Redes, enfoques y aplicaciones del análisis de redes sociales. Santiago de Chile: IDEA.USACH - Universidad Bolivariana. 
Berry, J. W. (1997) “Inmigration, acculturarion and adaptation" , Applied Psychology: an International Review, 46 (1), 5-61.

De Federico, Ainoa (2004): Los espacios sociales de la transnacionalidad. Una tipología de la integración relacional de los migrantes, Revista Redes, Vol. 7, Octubre Noviembre. http://revistaredes.rediris. es.

Ferrand, Alexis (2002). "Las comunidades locales como estructuras meso", Revista Redes, Vol. 3 \#4, Septiembre-Noviembre. http://revistaredes.rediris.es.

Mccarty, Chris (2002). "Structure in Personal Networks", JoSS. http://www. library.cmu.edu: 7850/JoSS/McCarty/McCarty.htm

Guarnizo, Luis (2007) "Aspectos económicos del vivir transnacional”, en: Ariza M. y Portes A. (eds.) El país transnacional: migración mexicana y cambio social a través de la frontera, Universidad Nacional Autónoma de México, Instituto de Investigaciones Sociales. México.

Guarnizo, Luis y Alejandro Portes (2003) "Assimilation and Transnationalism: determinants of transnational political action among contemporary migrants", American J ournal of Sociology, Volumen 108, núm. 6. pp 1211-48.

Molina, José Luis (2007). "El estudio de las redes personales: contribuciones, métodos y perspectivas", Empiria, Julio-Diciembre 10 (71-106).

Maya Jariego, Isidro (2002). "Tipos de redes personales de los inmigrantes y adaptación psicológica, Revista Redes, Vol.1, \#4, enero http://revistaredes.rediris.es

Maya Jariego, I. (2004). Sentido de comunidad y potenciación comunitaria. Apuntes de Psicología, 22 (2), 187-211

Portes, Alejandro (2007) “Un diálogo norte-sur: el progreso de la teoría en el estudio de la migración internacional y sus implicaciones", en: Ariza M. y Portes A. (eds.). El país transnacional: migración mexicana y cambio social a través de la frontera, Universidad Nacional Autónoma de México, Instituto de Investigaciones Sociales. México.

Portes, Alejandro, Luis Guarnizo y Patricia Landlot (2003). La globalización desde abajo: transnacionalismo inmigrante y desarrollo. La experiencia de Estados Unidos y América Latina. México: Ed. FLACSO.

Portes, Alejandro y Guarnizo, Luis (2002) "Transnacional entrepreneurs: the emergence and determinants o fan alternative form of immigrant economic adaptation". American sociological Review 67. 278-298. 
Vertovec, Steven, (2002) migration and other modes of transnationalism: towards conceptual cross-fertilization. Working paper, Red internacional de Migración y Desarrollo. México.

- (2003) Migrant transnationalism and modes of transformation. Working Paper Red Internacional para la Migración y el Desarrollo, México.

- (2007) Super-diversity and its implications. Ethnic and Racial Studies, vol 30, núm 6, pp 1024-1054.

Wellman, Barry, Peter J. Carrington, and Alan Hall (1988)."Networks as personal communities" en Wellman \& Berkowitz (eds.), Social Structures; A Network Approach. Cambridge University Press, Cambridge, 1988, pp. 130- 184.

Wellman, Barry (1996): "Are personal communities local? A Dumptarian reconsideration", Social Networks 18 (1996) 347-354. 